\title{
Suppression of stress induction of the 78-kilodalton glucose regulated protein (GRP78) in cancer by IT-139, an anti-tumor ruthenium small molecule inhibitor
}

\author{
Suzanne J. Bakewell' ${ }^{1}$, Daisy F. Rangel ${ }^{2}$, Dat P. Ha ${ }^{2}$, Jyothi Sethuraman ${ }^{1}$, Richard \\ Crouse $^{1}$, Emma Hadley ${ }^{2}$, Tara L. Costich ${ }^{1}$, Xingliang Zhou ${ }^{2}$, Peter Nichols ${ }^{3}$ and Amy \\ S. Lee $^{2}$ \\ ${ }^{1}$ Intezyne Technologies, Inc., Tampa 33612, FL, USA \\ ${ }^{2}$ Department of Biochemistry and Molecular Medicine, University of Southern California, Keck School of Medicine, USC Norris \\ Comprehensive Cancer Center, Los Angeles 90089, CA, USA \\ ${ }^{3}$ Department of Pathology, University of Southern California, Keck School of Medicine, USC Norris Comprehensive Cancer \\ Center, Los Angeles 90089, CA, USA
}

Correspondence to: Amy S. Lee, email: amy.lee@usc.edu

Keywords: small molecule inhibitor; IT-139; GRP78; ER stress; cancer

Received: February 23, $2018 \quad$ Accepted: June 01, $2018 \quad$ Published: July 03, 2018

Copyright: Bakewell et al. This is an open-access article distributed under the terms of the Creative Commons Attribution License 3.0 (CC BY 3.0), which permits unrestricted use, distribution, and reproduction in any medium, provided the original author and source are credited.

\section{ABSTRACT}

In many cancers, combination therapy regimens are successfully improving response and survival rates, but the challenges of toxicity remain. GRP78, the master regulator of the unfolded protein response, is emerging as a target that is upregulated in tumors, specifically following treatment, and one that impacts tumor cell survival and disease recurrence. Here, we show IT-139, an antitumor small molecule inhibitor, suppresses induction of GRP78 from different types of endoplasmic reticulum (ER) stress in a variety of cancer cell lines, including those that have acquired therapeutic resistance, but not in the non-cancer cells being tested. We further determined that IT-139 treatment exacerbates ER stress while at the same time suppresses GRP78 induction at the transcriptional level. Our studies revealed a differential effect of IT139 on chaperone protein family expression at multiple levels in different cancer cell lines. In xenograft studies, IT-139 decreased BRAF inhibitor upregulation of GRP78 expression in the tumor, while having minimal effect on GRP78 expression in the adjacent normal cells. The preferential decrease in GRP78 levels in tumor cells over normal cells, supported by the manageable safety profile seen in the Phase 1 clinical trial, reinforce the value IT-139 brings to combination therapies as it continues its clinical development.

\section{INTRODUCTION}

An emerging target that plays a critical role in tumor cell survival, tumor progression, and drug resistance is the 78-kDa glucose-regulated protein (GRP78), also known as the immunoglobulin binding protein $(\mathrm{BiP})$ and heat shock protein A5 (HSPA5) [1]. In non-stressed normal cells GRP78 resides in the endoplasmic reticulum (ER) where it regulates the integrity of the ER and the correct folding of newly synthesized proteins [2]. It functions by binding $\mathrm{Ca}^{2+}$ to maintain metabolic homeostasis and facilitates the export of misfolded proteins for degradation. GRP78 also forms complexes with ER transmembrane stress sensors: activating transcription factor 6 (ATF6), inositol-requiring enzyme 1 (IRE1), and PKR-like ER kinase (PERK) and maintains them in inactive forms [3]. Under ER stress, misfolded proteins accumulate and GRP78, a hydrophobic protein, binds to the accumulating malfolded proteins to 
alleviate their aggregation. As GRP78 is titrated away from ATF6, PERK, and IRE1, the unfolded protein response (UPR) is initiated. The UPR, along with other major mechanisms that include translation attenuation, increased expression of ER chaperones, enhanced ERassociated protein degradation and apoptosis, represents an evolutionarily conserved adaptive response that allows cells to overcome proteotoxic stress $[4,5]$. Thus, the UPR is an important survival pathway utilized by cancer cells.

GRP78 is expressed in all cell types as an essential chaperone for the synthesis of membrane-bound and secreted proteins processed through the ER [2]. Both young and aged Grp 78 heterozygous mice expressing $50 \%$ of wild type GRP78 level are phenotypically normal demonstrating that normal cells can tolerate partial GRP78 down-regulation without adverse effects [6-8]. Nonetheless, in multiple mouse cancer models, Grp 78 heterozygosity potently suppresses tumorigenesis, revealing that cancer progression requires a high level of GRP78, consistent with an elevated level of GRP78 in a wide range of human cancers $[1,7,9-11]$. Therefore, a drug that targets this up-regulation of GRP78, but not the constitutive, basal level of GRP78 could hypothetically present with decreased toxicity effects.

In tumorigenesis, GRP78 induction is mediated not only by intrinsic ER stress, but also as a result of extrinsic factors such as hypoxia and acidosis in the tumor microenvironment. In addition to the requirement of GRP78 for tumor progression and for cancer cell proliferation, tumor-associated endothelial cells also express a high level of GRP78 compared to endothelial cells of normal organs, and GRP78 is required for neoangiogenesis during tumor growth as well as chemoresistance of tumor-associated endothelial cells $[12,13]$. GRP78 elevation in tumor cells has been shown to confer resistance to chemotherapeutic drugs, including cisplatin, 5-FU, paclitaxel, docetaxel, sorafenib, bortezomib, etoposide, doxorubicin, temozolomide, vinblastine and camptothecins, as well as anti-hormonal, anti-angiogenesis, chromatin-modifying agents and radiation therapy [1, 14-17]. Decreasing the up-regulation of GRP78 in response to treatment potentially reduces resistance and thereby should increase efficacy of current standard of care therapies.

The various cellular locations of GRP78 correlate with the diverse biological activity of the protein in the cancer cell [18]. ER stress also induces alternative splicing of GRP78 that results in a cytosolic isoform (GRP78va) with a prosurvival function [19]. ER stress also translocates GRP78 from the ER to the mitochondria which is functionally and physically interconnected to the ER [20]. Recently it was discovered that ER stress actively promotes GRP78 to localize to the cell surface [21-23], where it functions as a co-receptor for various ligands [18, 24, 25]. An important function of GRP78 at the cell surface is to serve as an upstream regulator of PI3K-AKT oncogenic signaling, but GRP78 itself is also a downstream target of AKT activation [22, 26, 27]. Suppressing GRP78 up-regulation in response to ER stress also negatively impacts GRP78 relocalization to other sites, thereby also inhibiting these biological pathways controlled by GRP78 outside the ER.

GRP78 is a potent anti-apoptotic protein and can suppress apoptosis by several mechanisms depending on context. GRP78 binds caspase-7 (which is localized to the ER) to prevent its activation, and sequesters BIK to release BCL-2 [28, 29]. GRP78 also binds to mitochondrial and cell surface proteins that are involved in apoptotic pathways [30]. When tumor-initiating cells (TICs) in certain tumors express GRP78 on the cell surface, there is an association with self-renewal and suppression of differentiation and radioresistance, suggesting GRP78 surface expression may be a novel biomarker of TICs [31]. Translating this data into the clinic, the circulating plasma level of GRP78 measured from liquid biopsies may potentially identify patient responders and support personal therapy regimens.

Small molecule agents that interfere with the synthesis, stability or activity of GRP78 in cancer cells can suppress its function at various cellular locations. Blocking the stress induction of GRP78 is particularly attractive since a high level of GRP78 is required for tumorigenesis and is in contrast to normal cells that only need a basal level of GRP78 for cell maintenance. Therefore, the impedance of GRP78 induction under stress conditions is expected to suppress tumor growth, tumor angiogenesis, invasion, metastasis and stem cell survival while sparing unstressed normal cells.

It has recently been shown that combination therapies will be necessary to avoid the emergence of drug resistance in solid tumors [32]. However, the challenge with combination therapy is the increase in drug-drug interaction [33] and limiting patient toxicities [34]. Many preclinical studies will evaluate sensitivity to targeted drugs, but do not evaluate the effect on normal cells, nor the potential for overlapping toxicities in the patient, which are therefore dependent on empirical clinical trials.

IT-139, sodium trans-[tetrachlorobis(1H-indazole) ruthenate(III)], is an intravenously administered small molecule compound that in a US Phase 1 single agent study was well tolerated with modest anti-tumor activity [35]. Side effects were manageable at the maximum tolerated dose of $625 \mathrm{mg} / \mathrm{m}^{2}$ and did not include marrow suppression associated with standard cytotoxins. Here, we show that IT-139 is effective in suppressing the stress induction of GRP78 in a wide range of cancer cells via multiple mechanisms but has minimal effect on GRP78 stress induction in the normal human cell lines and primary cells that we tested. In xenograft models, IT139 alone is capable of suppressing GRP78 expression in tumors but is more effective in combination with chemotherapy. GRP78 level in surrounding normal tissues is not affected. The selective down-regulation of GRP78 
in tumors not only provides one mechanistic explanation for the anti-neoplastic activity of this novel compound, but also suggests potential for combination therapy in the clinic with a limited associated increase in toxicity.

\section{RESULTS}

\section{IT-139 is a ruthenium-containing small molecule antitumor drug capable of suppressing stress induction of GRP78}

IT-139 (Figure 1A) was selected from a library of ruthenium compounds for its anti-tumor activity in a broad range of human cancer cell lines [36]. The ruthenate anion is susceptible to hydrolysis in aqueous solutions [37], but theoretically is thought to be suppressed in humans by binding to albumin and proteins $[38,39]$. To determine if ruthenium is the active metabolite of IT-139 we treated HCT116 colon carcinoma cells with IT-139 and compared the results to the toxicity of ruthenium chloride $\left(\mathrm{RuCl}_{3}\right)$. Cytotoxicity in these studies is defined as the maximal concentration that inhibits the viability of cells by $50 \%$ (IC50), or the half-maximal effective concentration (EC50) that induces a response compared to untreated control cells at $72 \mathrm{hrs}$. The IC50 and EC50 of IT-139 in the majority of cell lines tested are in the micromolar $(\mu \mathrm{M})$ range (Table 1). We treated HCT116 colon carcinoma cells with $\mathrm{RuCl}_{3}$ and compared the IC50 to that of IT139 treatment. The IC50 of IT-139 in HCT116 cells was $167 \mu \mathrm{M}$, but $\mathrm{RuCl}_{3}$ showed little toxicity and $50 \%$ viability was not reached at 72 hours (not shown).

To further determine if the ruthenate anion is the active moiety of IT-139, we compared by immunoblot the effect of $\mathrm{RuCl}_{3}$ on GRP78 protein levels in HCT116 cells after 16 hours, compared to GRP78 protein levels after 200 $\mu \mathrm{M}$ IT-139 treatment at the same time point (Figure 1B). Thapsigargin (Tg) is a sarco/endoplasmic reticulum $\mathrm{Ca}^{2+}$ ATPase (SERCA) inhibitor that induces endoplasmic reticulum (ER) stress by blocking $\mathrm{Ca}^{2+}$ reuptake into the ER. $300 \mathrm{nM}$ of Tg treatment for 16 hours increased GRP78 levels 3-fold in HCT116 cells. Tg-induced GRP78 protein levels were reduced by IT-139 treatment to below 1.5-fold compared to control levels, but $\mathrm{RuCl}_{3}$ treatment did not affect Tg-induced GRP78 levels, further suggesting that the ruthenate anion is not the active moiety.

\section{The effect of IT-139 on the stress induction of GRP78 in human cells}

GRP78 protein levels are elevated in stressed human cells. To determine whether IT-139 treatment affects stress induction of GRP78 in normal human cells, we utilized the HEK-293T (293T) human embryonic kidney cell line. The $293 \mathrm{~T}$ cells were treated with IT139 alone or in the presence of Tg. We observed that in both non-stressed and Tg-stressed cells, IT-139 up to
$200 \mu \mathrm{M}$ showed no or minimal effect on GRP78 protein levels, whereas a stimulatory effect was observed at 500 $\mu \mathrm{M}$ (Figure 1C). Next, we examined the effect of IT-139 on the promoter activity of the GRP78 gene. For these experiments, we utilized a $293 \mathrm{~T}$ stable cell line harboring the -169-luciferase construct which contains the three ER stress response elements of the rat GRP78 promoter fused to a luciferase reporter gene [40]. IT-139 treatment alone at $200 \mu \mathrm{M}$ showed no effect on the luciferase activity, but in Tg-treated cells, IT-139 further increased the luciferase activity by about 2 -fold (Figure 1D).

IT-139 treatment had no effect on GRP78 protein levels in non-stressed primary astrocytes (Figure 1E) or HUVEC primary human endothelial cells (Figure 1F). Combination treatment with IT-139 and Tg in primary astrocytes did not see a change in GRP78 levels over Tg treatment alone (Figure 1E). Interestingly, in contrast to mature endothelial cells in normal organs that exhibit low proliferative rates, HUVECs in culture resemble fast proliferating tumor-associated endothelial cells [13]. We observed about a 1.3-fold decrease in GRP78 levels with $200 \mu \mathrm{M}$ IT-139 in combination treatment with Tg (Figure $1 \mathrm{~F})$.

\section{IT-139 suppresses stress induction of GRP78 in both androgen-dependent and resistant prostate cancer cell lines and exacerbates ER stress}

To compare the effect of IT-139 on therapeutic resistant human cancer cells, we utilized C4-2B (androgen-independent) and LNCaP-FGC (androgendependent) human prostate cancer cell lines. The cells were treated with IT-139 alone or in combination with $\mathrm{Tg}$. The levels of GRP78 mRNA were detected by RTPCR (Figure 2A) and the levels of GRP78 protein were detected by Western blot (Figure 2B). Our results showed that IT-139 at 200 and $500 \mu \mathrm{M}$ was effective to suppress the Tg-induction of GRP78 at both the mRNA and protein level. For non-stressed cells, IT-139 showed suppression of GRP78 mRNA in both cell lines, but not at the level of GRP78 protein, which is a stable protein with a long half life. A mild elevation of GRP78 mRNA in the C4-2B cells at the $500 \mu \mathrm{M}$ dose suggests induction of ER stress.

At the onset of the UPR, a hallmark is eIF $2 \alpha$ phosphorylation to suppress translation. However, eIF $2 \alpha$ activation is transient and usually subsides after $8 \mathrm{hr}$. For both C4-2B and LNCaP-FGC cells, IT-139 (500 $\mu \mathrm{M})$ caused a 2 - and 5 to 7 -fold increase in phosphorylation of eIF $2 \alpha$ in non-stressed and Tg-stressed cells, respectively (Figure 2C). LNCaP cells were more sensitive as $200 \mu \mathrm{M}$ elicited some effect already. The activation was detected at $16 \mathrm{hr}$, suggesting a sustained effect. The drug has little effect on the level of total eIF $2 \alpha$ or $\beta$-actin, which served as loading control for the Western blots (Figure 2D). The activation of eIF $2 \alpha$ correlated with the depletion of GRP78 under these conditions. 
Table 1: $\mathrm{IC}_{50}$ and $\mathrm{EC}_{50}$ cell viability assay

\begin{tabular}{|c|c|c|c|c|c|}
\hline \multirow{2}{*}{ Cell line } & \multicolumn{2}{|c|}{ IC50 $(\mu \mathrm{M})$} & \multirow{2}{*}{ Cell line } & \multicolumn{2}{|c|}{$\mathrm{EC50}(\mu \mathrm{M})$} \\
\hline & IT-139 & Cisplatin & & IT-139 & Cisplatin \\
\hline Capan-1 & 34.7 & 2.0 & BxPC-3 & 27.1 & 2.7 \\
\hline НCТ116 & 167.0 & 11.5 & Capan-1 & 45.2 & 10.6 \\
\hline НТ-29 & 15.2 & 20.3 & DU 145 & 80.8 & 49.5 \\
\hline A549 & 148.0 & 6.6 & NCI-H322M & 159.0 & 52.3 \\
\hline A375 & 130.0 & 2.6 & H1975 & 33.6 & 11.4 \\
\hline \multirow[t]{8}{*}{ SKMEL-5 } & 144.0 & 6.2 & LNCaP & 17.3 & 10.3 \\
\hline & & & MCF-7 & 37.8 & 8.0 \\
\hline & & & MIAPaCa-2 & 57.4 & 21.1 \\
\hline & & & MX-1 & 104.0 & 16.0 \\
\hline & & & N87 & 3.7 & 21.3 \\
\hline & & & PANC-1 & 30.6 & 11.1 \\
\hline & & & PC-3 & 41.8 & 18.7 \\
\hline & & & ZR-75-1 & 18.1 & 17.5 \\
\hline
\end{tabular}

Another hallmark of UPR activation is splicing of the XBP-1 mRNA. IT-139 at $500 \mu \mathrm{M}(16 \mathrm{hr})$ caused mild $X B P-1$ mRNA splicing in non-stressed C4-2B and LNCaP cells. IT-139 at $500 \mu \mathrm{M}$ caused large increase in $X B P-1$ mRNA splicing in Tg-stressed C4-2B and LNCaP prostate cancer cell lines, consistent with GRP78 depletion (Figure 2E). Collectively, these results showed that IT-139 not only does not impair induction of the eIF $2 \alpha$ or XBP arm of UPR, it exacerbates them.

\section{IT-139 can suppress induction of GRP78 by different types of ER stress in multiple human cancer cells}

To address the lowest effective dose of IT-139 in suppressing GRP78 stress induction and whether this suppression can be observed with another ER stress inducer such as tunicamycin $(\mathrm{Tu})$ which blocks N-linked glycosylation, we treated HCT116 cells with doses of IT139 ranging from 50 to $500 \mu \mathrm{M}$, alone or in combination with $\mathrm{Tg}$ and $\mathrm{Tu}$ (Figure $3 \mathrm{~A}$ ). Our results showed that for either Tg or Tu induction, $250 \mu \mathrm{M}$ of IT-139 was sufficient to decrease GRP78 stress upregulation at the protein level. Suppression of Tg-induced GRP78 protein expression at $200 \mu$ M IT-139 was also observed in HepG2 (liver) human cancer cells (Figure 3B).

\section{IT-139 suppresses $G R P 78$ at the transcriptional level}

To further investigate the effect of IT-139 on GRP78 transcription, HCT116 cells were treated with $\mathrm{Tu}$ in the presence or absence of IT-139 ranging from 200 to 500 $\mu \mathrm{M}$ and assayed for GRP78 mRNA level by RT-PCR. As expected, Tu treatment resulted in an increase in GRP78
mRNA levels, but in the presence of IT-139 there was a decrease in GRP78 mRNA levels and that treatment with $200 \mu \mathrm{M}$ of IT-139 for $4 \mathrm{hr}$ was sufficient to nearly eliminate Tu induction of GRP78 mRNA (Figure 4A). Similarly, Tginduced elevation of GRP78 mRNA was suppressed by IT-139 (Figure 4B). In these cells, an increasing dosage of IT-139 treatment alone was able to reduce GRP78 mRNA levels incrementally in non-stressed cells (Figure 4C). The decrease in GRP78 promoter activity after treatment with $200 \mu \mathrm{M}$ of IT-139 was also observed in non-stressed and Tg-stressed HCT116 cells, as measured by the luciferase activity in such cells transiently transfected with -169 Luciferase construct which contains the ER stress response elements of the rat Grp 78 promoter driving the expression of the luciferase gene [40] (Figure 4D). The ability of IT139 to suppress Tg-induced increase in GRP78 mRNA was confirmed in HT-29 and HepG2 cells (Supplementary Figure 1).

\section{Differential effect of IT-139 on chaperone protein family expression}

To expand our analysis on the effect of IT-139 on gene expression, we analyzed additional human cancer cells. SK-MEL-28 (melanoma) and A549 (lung) were assayed for mRNA and protein level of ER chaperones [GRP78, GRP94, calreticulin (CRT)] and a cytosolic chaperone HSP70. The cells were either non-stressed or treated with Tu and subjected to 0 to $250 \mu \mathrm{M}$ of IT-139.

In SK-MEL-28 cells, IT-139 mildly increased GRP78 mRNA at high dose, while moderately suppressed its protein levels in non-stressed cells (Figure 5A, Supplementary Figure 2). It suppressed GRP94 mRNA, but not protein levels. Tu-induction of GRP78 mRNA and protein were potently suppressed at $100 \mu \mathrm{M}$ to $200 \mu \mathrm{M}$ 
A<smiles>[BiH]</smiles>

B
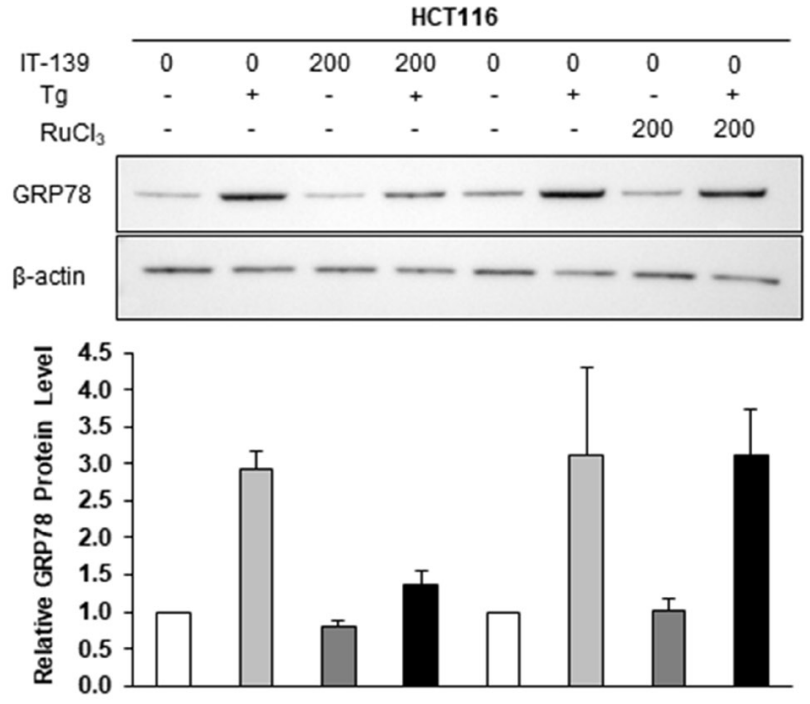

C
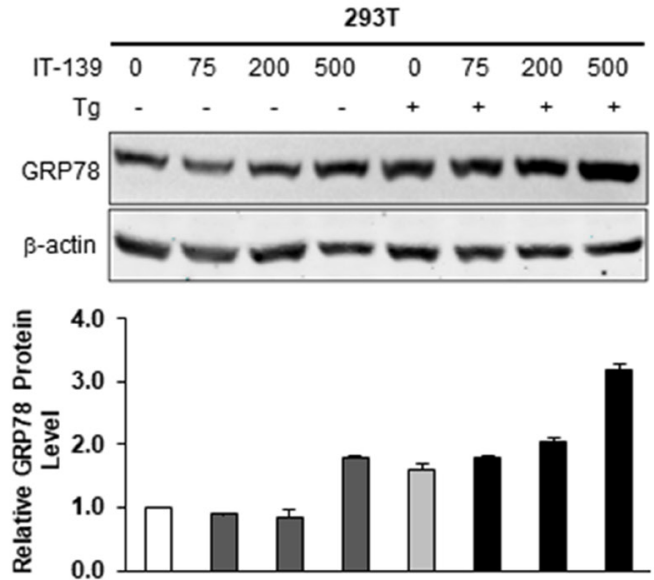

E
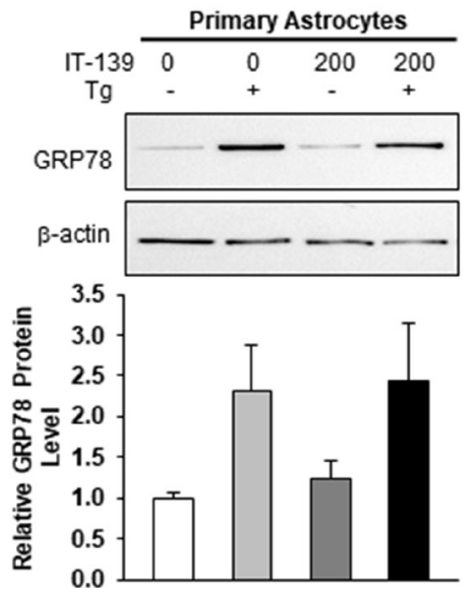

D
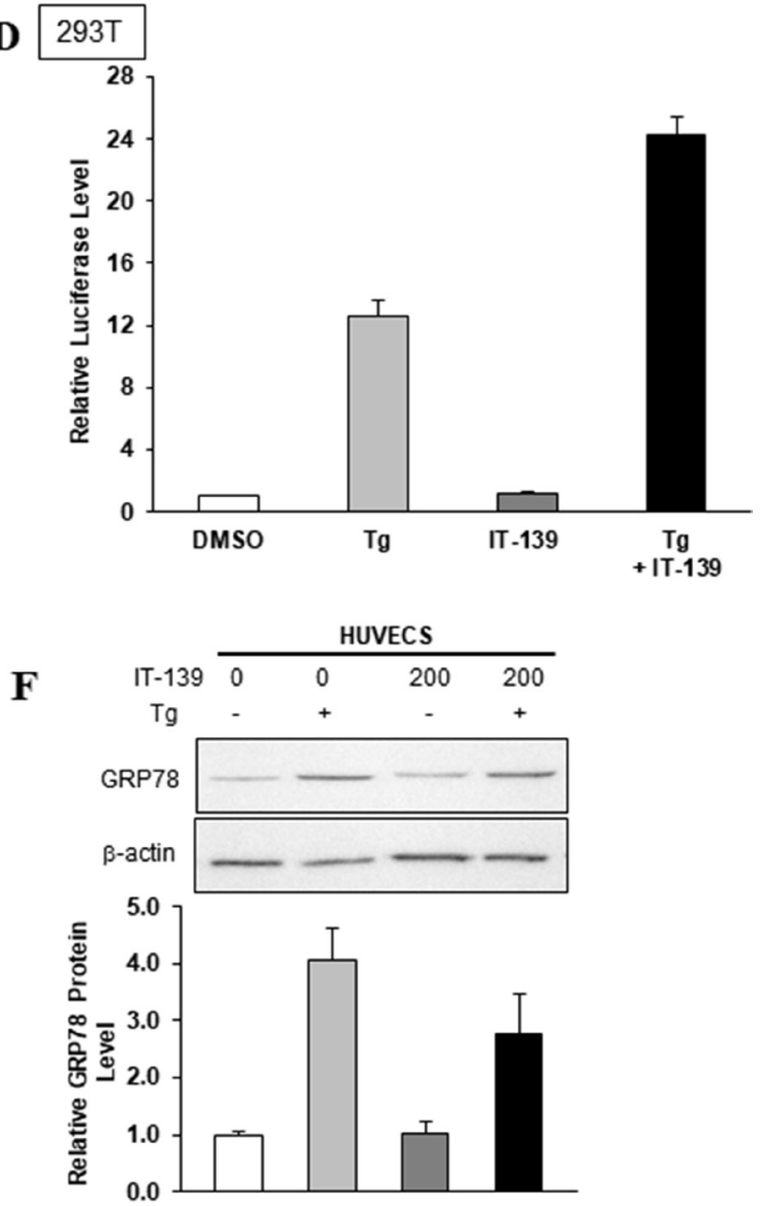

Figure 1: IT-139 molecule and its effects on human cells. (A) Chemical structure of IT-139: sodium trans-[tetrachlorobis(1Hindazole)ruthenate(III)] (molecular weight $502.15 \mathrm{~g} / \mathrm{mol}$ and formula $\mathrm{C}_{14} \mathrm{H}_{12} \mathrm{Cl}_{4} \mathrm{~N}_{4} \mathrm{RuNa}$ ). (B) Effect of IT-139 and RuCl3 on GRP78 protein in treated HCT116 cells. Relative GRP78 protein levels were measured after 16 hours of treatment by Western blot with $\beta$-actin serving as loading control. The band intensities were quantitated and graphed below. Tg: thapsigargin. (C) HEK-293T cells were treated with the indicated dosages of IT-139 $(0-500 \mu \mathrm{M})$ for 16 hours and assayed for GRP78 protein levels. (D) HEK-293T stable cell line harboring the -169-luciferase construct was treated with Tg alone or in combination for 16 hours with $200 \mu \mathrm{M}$ IT-139 as indicated and assayed for luciferase activity. (E) Relative GRP78 protein levels in primary astrocytes after $200 \mu \mathrm{M} \mathrm{IT-139}$ treatment alone or in combination with Tg. (F) Relative GRP78 protein levels in HUVECS after $200 \mu \mathrm{M}$ IT-139 treatment alone or in combination with Tg. 

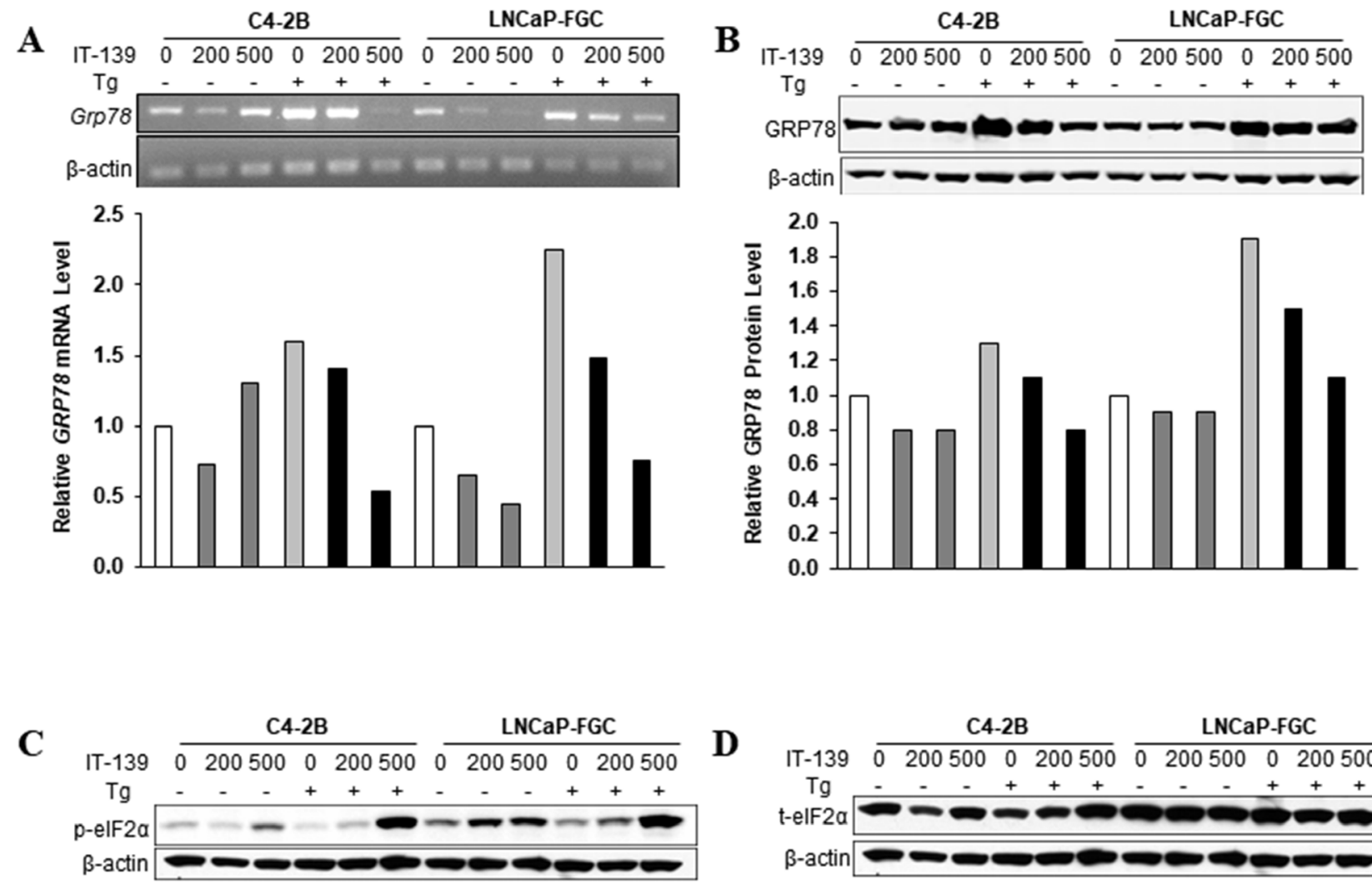

D
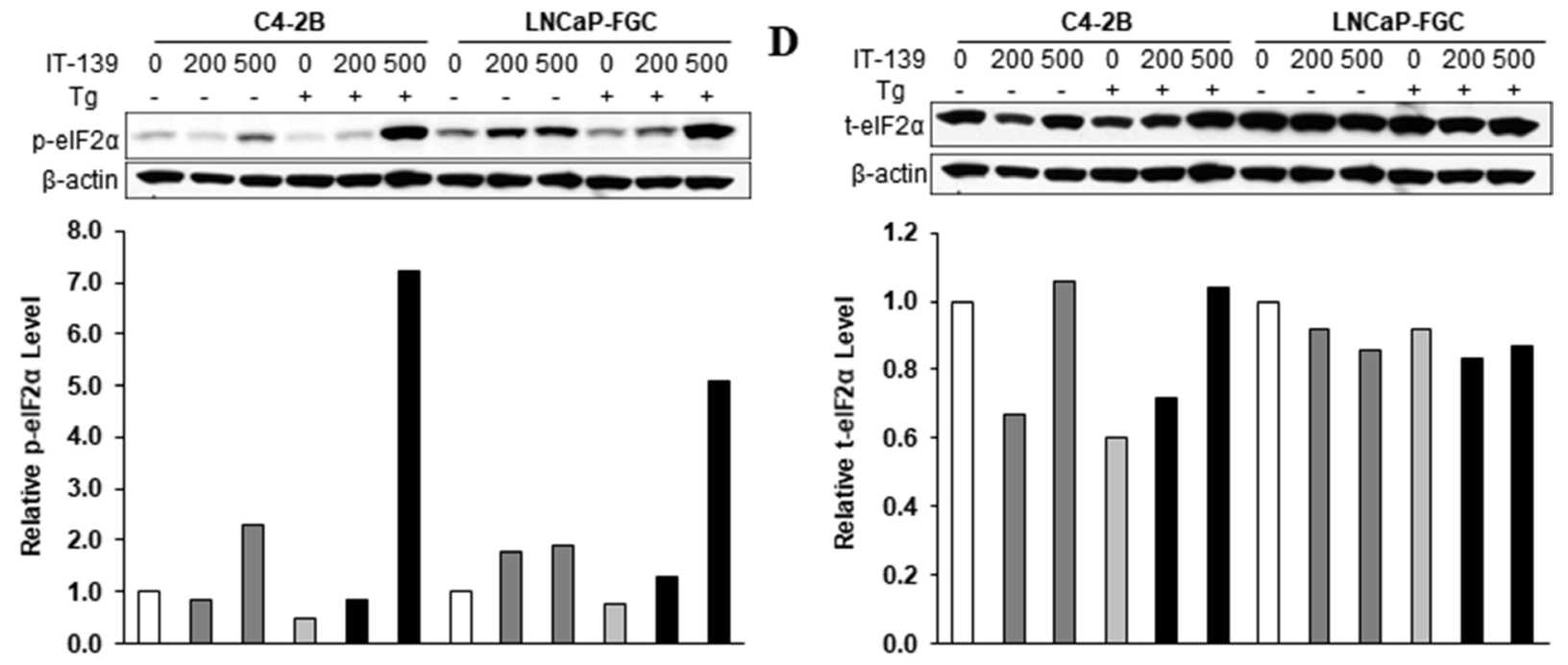

E

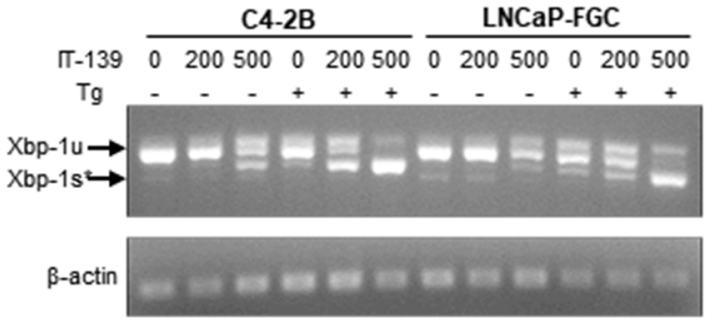

Figure 2: IT-139 specifically suppresses stress induction of GRP78 mRNA and protein. (A) Prostate cancer cell lines C4-2B and LNCaP-FGC were treated with $200 \mu \mathrm{M}$ and $500 \mu \mathrm{M}$ IT-139 alone or in the presence of Tg. GRP78 mRNA levels were suppressed in both cell lines in stressed and non-stressed conditions. (B) Protein levels detected by Western blot showed suppression of GRP78 in stressed conditions in both cell lines. (C) Western blots showing protein levels of phosphorylated eIF2 $\alpha$ in stressed and non-stressed prostate cells. $500 \mu \mathrm{M}$ IT-139 results in an increase in eIF2 $\alpha$ levels in stressed conditions, and the effect is more sensitive in LNCaP-FGC cells. (D) Total eIF2 $\alpha$ protein levels are little affected by IT-139. (E) Splicing of XBP-1 mRNA was increased in stressed C4-2B and LNCaP-FGC cells. Tg: thapsigargin. Xbp-1u: unspliced. Xbp-1s: spliced. 

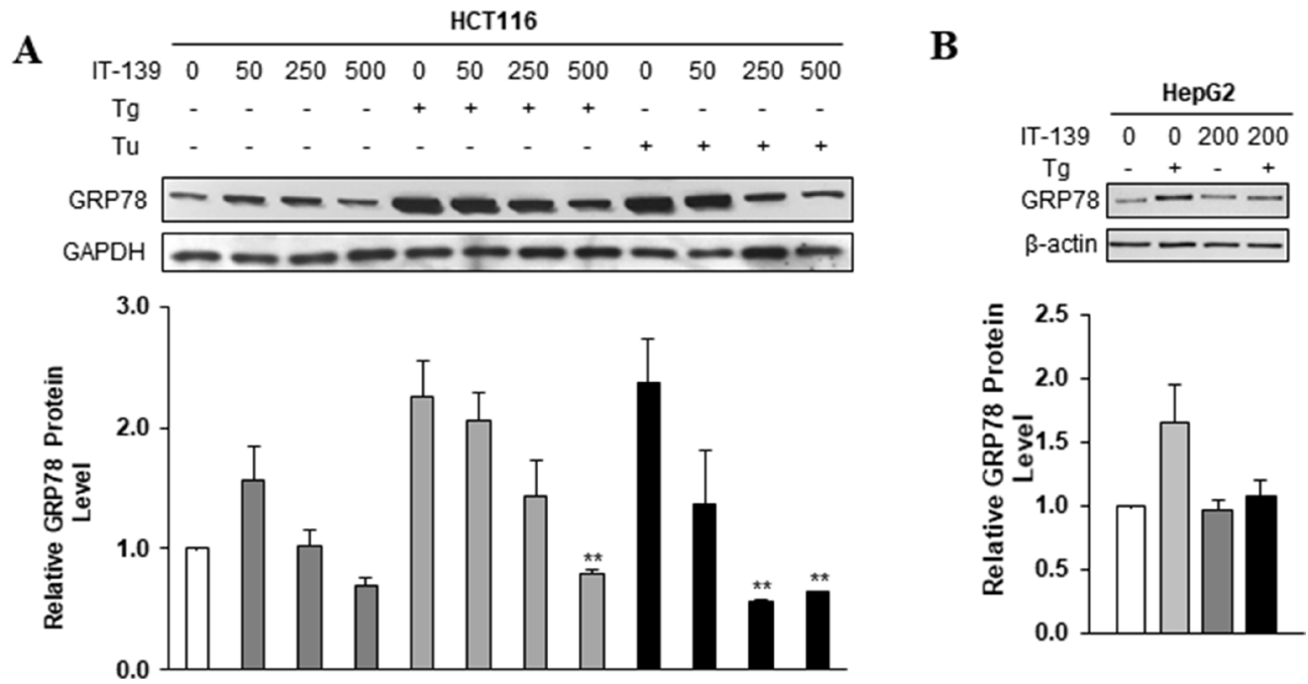

Figure 3: IT-139 suppresses induction of GRP78 by different ER stress inducers. (A) Colon carcinoma cell line HCT116 was treated with the indicated doses $(0-500 \mu \mathrm{M})$ of IT-139 alone or in the presence of Tg or Tu. GRP78 protein levels detected by Western blot show suppression of GRP78 under Tg and Tu-induced stress conditions. (B) Relative levels of GRP78 were analyzed in hepatocellular carcinoma (HepG2). IT-139 suppressed GRP78 levels under stress conditions. Tg: thapsigargin. Tu: tunicamycin.
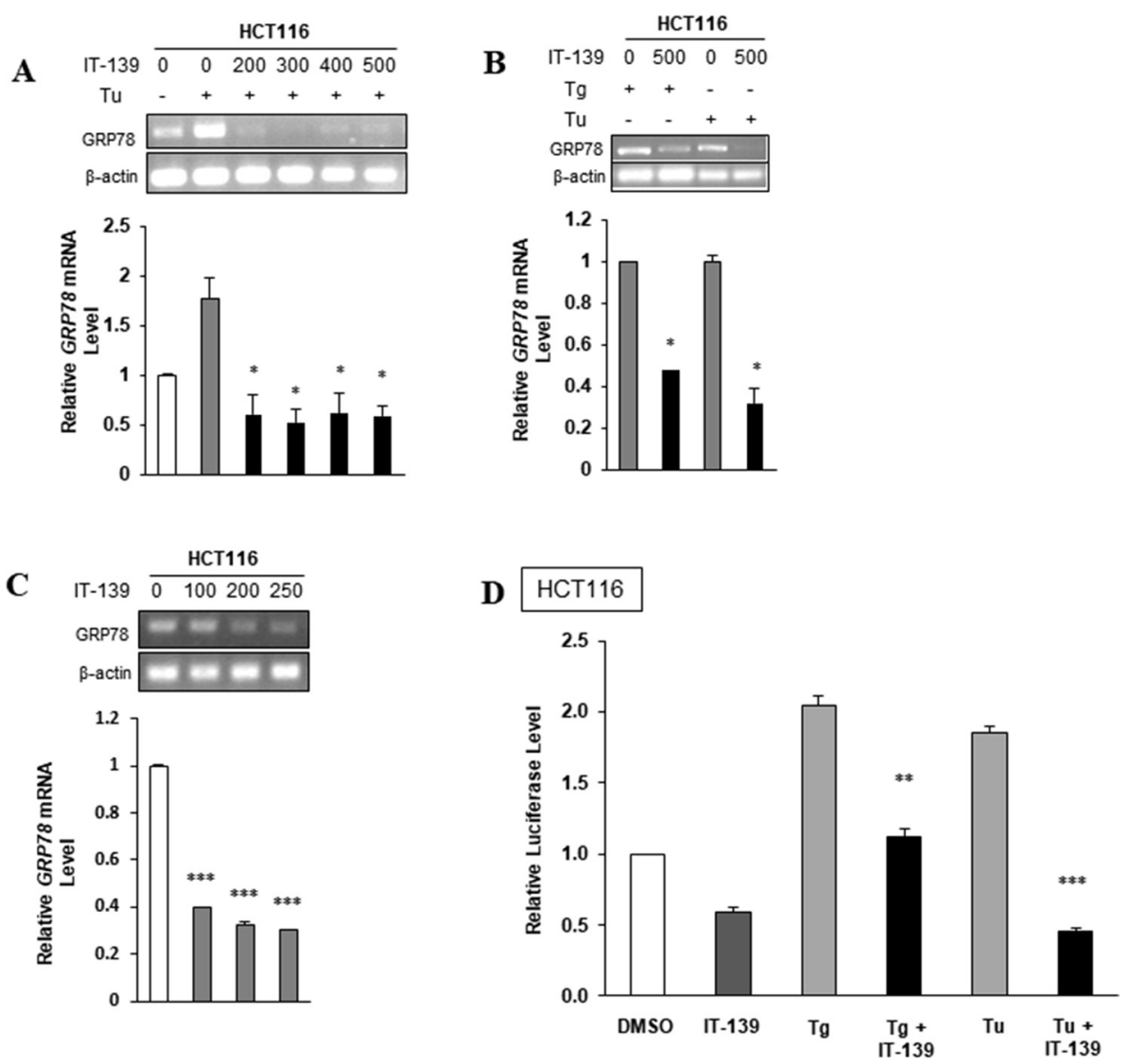

Figure 4: IT-139 suppresses GRP78 expression at the transcriptional level. (A) Colon carcinoma cell line HCT116 cells were treated with the indicated dosages of IT-139 $(0-500 \mu \mathrm{M})$ with or without Tu treatment. (B) HCT116 cells were treated with Tg or Tu alone or in the absence or presence of $500 \mu \mathrm{M}$ IT-139. (C) HCT116 cells were treated with the indicated dosage of IT-139 (0-250 $\mu \mathrm{M})$ for 4 hours and assayed for GRP78 mRNA levels. (D) HCT116 cells were transfected with the -169 luciferase and Renilla luciferase plasmids and treated with Tg, Tu and IT-139, alone or in combination as indicated and assayed for luciferase activity. 
range. GRP94 mRNA and protein were moderately suppressed. In contrast, CRT protein and HSP70 protein levels were upregulated, with no effect on HSP70 mRNA. Therefore, IT-139 suppresses GRP78 and GRP94 stressinduced expression at the transcriptional level, but upregulates HSP70 at the post-transcriptional level in SKMEL-28 cells.

In lung cancer A549 cells, IT-139 up to 250 $\mu \mathrm{M}$ had no effect on GRP78 mRNA, but moderately elevated its protein level in non-stressed cells (Figure 5B, Supplementary Figure 3). It suppressed GRP94 mRNA, but not protein. CRT protein was moderately upregulated and HSP70 mRNA was not affected, but protein was decreased. Tu-induction of GRP78 and GRP94 mRNA were not affected at $250 \mu \mathrm{M}$, but both GRP78 and GRP94 protein levels were potently suppressed. In contrast, in Tu-stressed cells, CRT protein, HSP70 mRNA and protein were not affected by IT-139. Therefore, IT-139 suppresses
GRP78 and GRP94 stress-induced expression at the posttranscriptional level in A549 cells.

\section{Over-expression of GRP78 rescues cells from IT- 139-induced apoptotic activities}

To determine the importance of GRP78 in the apoptotic action of IT-139, we transiently transfected HCT116 cells with a pcDNA3 vector expressing FLAGtagged GRP78 (F-GRP78) driven by the CMV promoter or the empty vector. Since transcriptional control of the CMV promoter is unaffected by IT-139, the expression of F-GRP78 in the transfected cells was not suppressed by IT-139 in contrast to endogenous GRP78 (Figure 6A). Over-expression of F-GRP78 was estimated to be about 2 -fold over the endogenous level (Figure 6B). Our results showed that this was sufficient to reduce IT-139-induced activation of the apoptotic markers PARP and Caspase-3
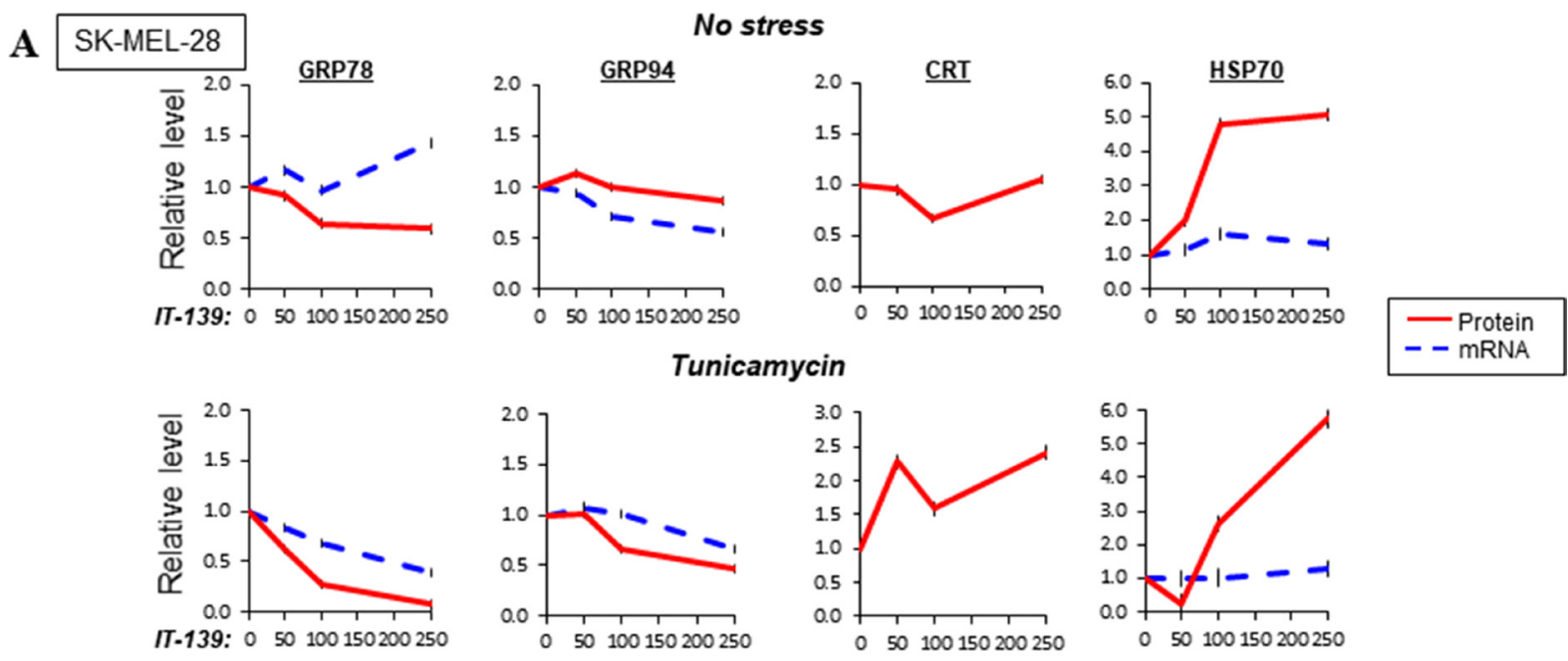

No stress
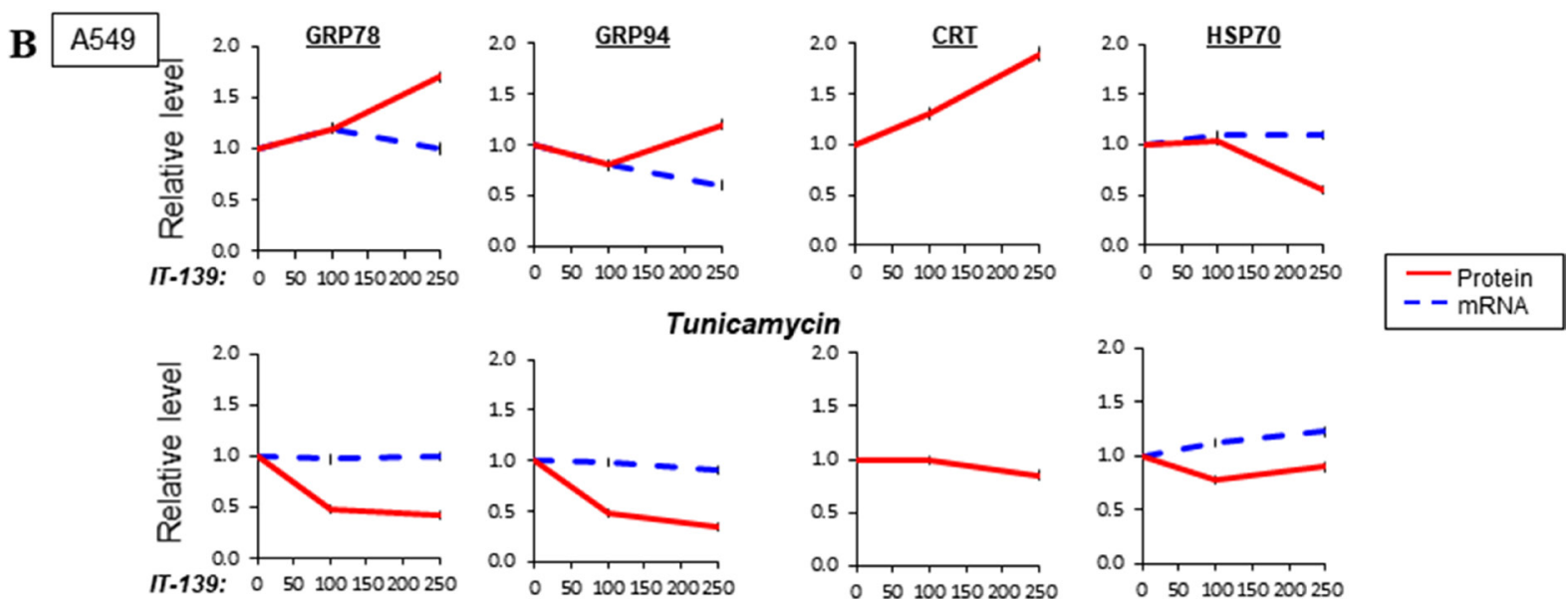

Figure 5: Effect of IT-139 on expression of chaperone protein family. (A) Relative levels of GRP78, GRP94, CRT and HSP70 in melanoma SK-MEL-28 cells treated with various dosages of IT-139. Protein levels, depicted by a solid line, and mRNA levels, depicted by dashed lines, were measured with or without Tu treatment. (B) Same as (A) except lung cancer A549 cells were examined. 
by about 50\%, under non-stressed and Tg-stressed conditions (Figures 6A and 6B). Collectively, these results indicate that GRP78 suppression contributes significantly to the apoptotic activities of IT-139, which can be rescued through GRP78 over-expression.

\section{IT-139 synergizes with standard therapy in vivo}

Combination index [41] results (Table 2) show IT139 synergism with most classes of cancer treatments, suggesting that it can potentially be administered in combination with standard anticancer therapies. We treated three xenograft in vivo models (HCT116, A549, and HT-29) with IT-139 at $30 \mathrm{mg} / \mathrm{kg}$ every four days, or $50 \mathrm{mg} / \mathrm{kg}$ once a week in combination with oxaliplatin, cisplatin or 5-FU respectively (Figures 7A-7C). In all models, IT-139 increased anti-tumor efficacy. Except for the $50 \mathrm{mg} / \mathrm{kg}$ dose in the A549 model (Figure 7B), it did not significantly increase toxicity as evaluated by average body weight of the group. Following the A549 cisplatin combination study, the dosing of the chemotherapeutic and IT-139 were staggered by 24 hours. In the HT-29 xenograft model (Figure 7C), we saw a response in antitumor growth with IT-139 in combination with 5-FU that was increased at the $50 \mathrm{mg} / \mathrm{kg}$ dose. However, the effect on body weight was reduced with the staggered dosing, with a maximum $8 \%$ loss compared to the $15 \%$ weight loss in the cisplatin group that was dosed in the same bolus as $50 \mathrm{mg} / \mathrm{kg}$ IT- 139 .

\section{IT-139 decreases GRP78 expression in treated tumors but not in adjacent normal cells}

In a BRAF-mutated in vivo xenograft study, we treated A375 melanoma tumor-bearing animals with a BRAF mutated inhibitor (PLX4720), IT-139 or both in combination. We harvested the tumors after 15 days, fixed in formalin and stained by immunohistochemistry for GRP78 expression. The A375 tumors from the vehicle (saline) group exhibited heterogeneous GRP78 expression within the tumor region with notably high expression at the necrotic borders (Figure 8A). The PLX4720 treated group had consistent strong GRP78 staining across the

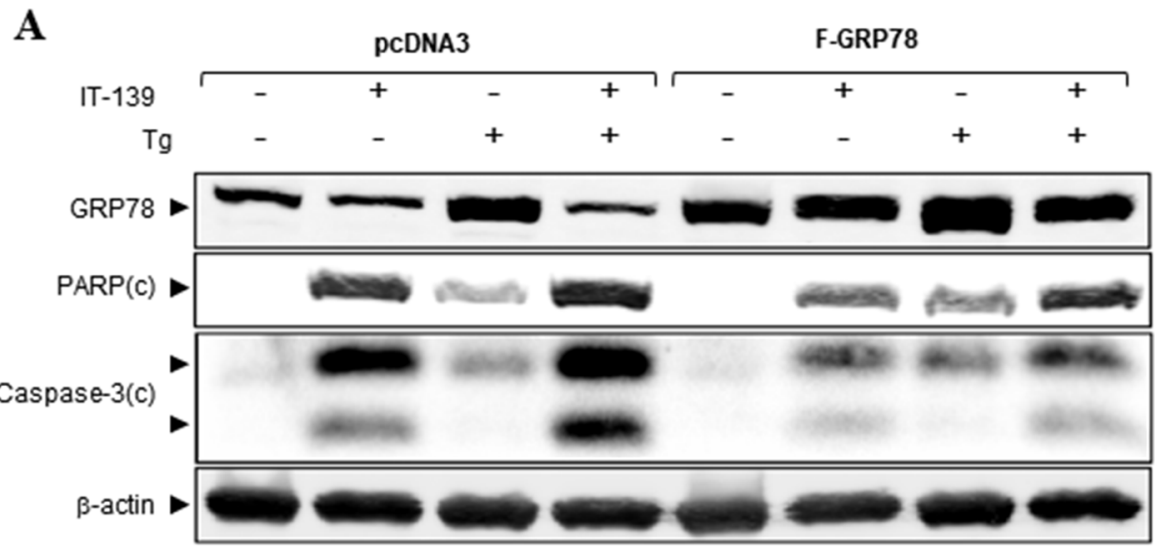

B

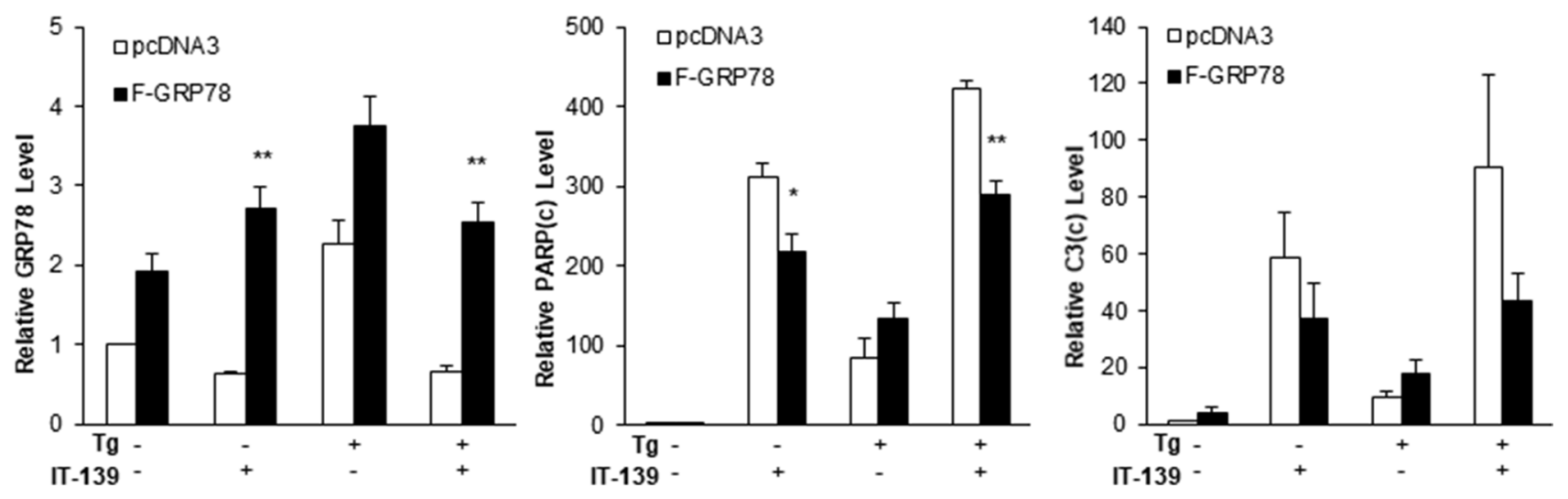

Figure 6: GRP78 over-expression alleviates IT-139-induced apoptotic activities. (A) HCT116 cells transfected with pcDNA3 empty vector or vector expressing FLAG-GRP78 were treated with IT-139 and Tg as indicated for $24 \mathrm{hr}$. Whole cell lysates were collected and the indicated proteins were analyzed by Western blot with $\beta$-actin as loading control. The cleaved form of PARP and Caspase- 3 were denoted as PARP(c) and Caspase-3(c). (B) The band intensities for the indicated proteins in (A) were quantified, normalized against $\beta$-actin and graphed. The relative levels are shown with standard error. 
Table 2: Combination treatment assay

\begin{tabular}{lccc}
\hline Therapeutic & Cell line & Cancer & Combination index \\
\hline CDDP & A549 & Lung & 0.172 \\
Paclitaxel & LNCaP & Prostate & 0.219 \\
Doxorubicin & Hep3B & Liver & 0.252 \\
Everolimus & MKL-1 & NET & 0.354 \\
5-FU & HCT-116 & Colon & 0.36 \\
Oxaliplatin & Lovo & Colon & 0.493 \\
Erlotonib & A549 & Lung & 0.509 \\
Sorafenib & Hep3B & Liver & 0.536 \\
Docetaxel & LNCaP & Prostate & 0.543 \\
5-FU & Lovo & Colon & 0.597 \\
Gemcitabine & A549 & Lung & 0.647 \\
CDDP & HCT-116 & Colon & 0.687 \\
Erlotonib & BxPC3 & Pancreatic & 0.691 \\
Docetaxel & A549 & Lung & 0.724 \\
CDDP & N87 & Gastric & 0.757 \\
Sorafenib & A549 & Lung & 0.846 \\
Gemcitabine & PANC-1 & Pancreatic & 0.895 \\
Paclitaxel & A549 & Lung & 1.01 \\
Gemcitabine & Capan-1 & Pancreatic & 1.02 \\
5-FU & ZR-75-1 & Breast \\
Docetaxel & N87 & Gastric & 1.05 \\
Paclitaxel & N87 & Gastric & 1.05 \\
\hline & & & 1.1 \\
\hline
\end{tabular}

Combination indices were calculated using the Chou-Talay method. Cells were exposed concomitantly to both drugs for 72 hours and cytotoxicity determined using the MTT assay. The Combination Index (CI) values were calculated using the Compusyn $^{\circledR}$ program. CI values of $0.90-1.10$ indicate additive effects. CI values of $<0.90$ indicate synergy (the smaller the value, the greater the degree of synergy).

tumor sections, whereas the IT-139/PLX4720 treated tumor sections showed greatly reduced GRP78 expression. Thus, PLX4720 appeared to induce higher expression levels of GRP78 that were decreased by combination treatment with IT-139. However, the GRP78 expression in the normal skin cells surrounding the tumor section was not affected by IT-139 treatment (Figure 8B).

\section{DISCUSSION}

GRP78 is highly expressed in a wide variety of cancers and controls multiple steps of tumorigenesis in response to environmental and therapeutic insult. GRP78's upregulation in tumor cells makes it an attractive target for anti-cancer therapy $[1,14]$. Considering that in tumor cells GRP78 can be localized to various cellular locations mediating pro-proliferation and survival functions, agents that inhibit the synthesis, stability or activity of GRP78 will be most effective in suppressing its function at the multiple locations. However, because GRP78 is an essential chaperone, the challenge of anti-GRP78 drug development is to minimize toxicity to normal organs. Heterozygous Grp 78 knockout mouse models in whole body as well as specific organs established that $50 \%$ decrease in GRP78 expression has no effect on normal organ function throughout the lifespan, but significantly impedes tumor growth and angiogenesis $[1,8,13]$. This suggests that in adult animals, agents that selectively block the stress induction of GRP78 will primarily affect tumors that require a higher level of GRP78 for proliferation, invasion and therapeutic resistance while sparing normal organs that only need a low basal level of GRP78 for maintenance. These agents should also be able to target tumor-associated cells that fuel cancer growth and require high GRP78 expression for their own growth and survival in the toxic tumor microenvironment.

The interest in GRP78 as a potential target for therapy is rapidly growing because of its pivotal role in ER stress, cell survival, and drug resistance. It has been reported that small molecule inhibitors such as versipelostatin, piericidin A, pyrvinium are able to suppress glucose starvation induction of GRP78, but not always following stress induction by either $\mathrm{Tu}$ or $\mathrm{Tg}$ [42-44]. This raises the issue 
whether these agents may actually target mitochondrial function and protein synthesis in general [42]. In this study, we investigated the effect of IT-139 on GRP78 expression in vitro and in vivo. IT-139 effectively suppresses the stress induction of GRP78 induced by both Tg and Tu, suggesting a distinct mode of action from the small molecule inhibitors
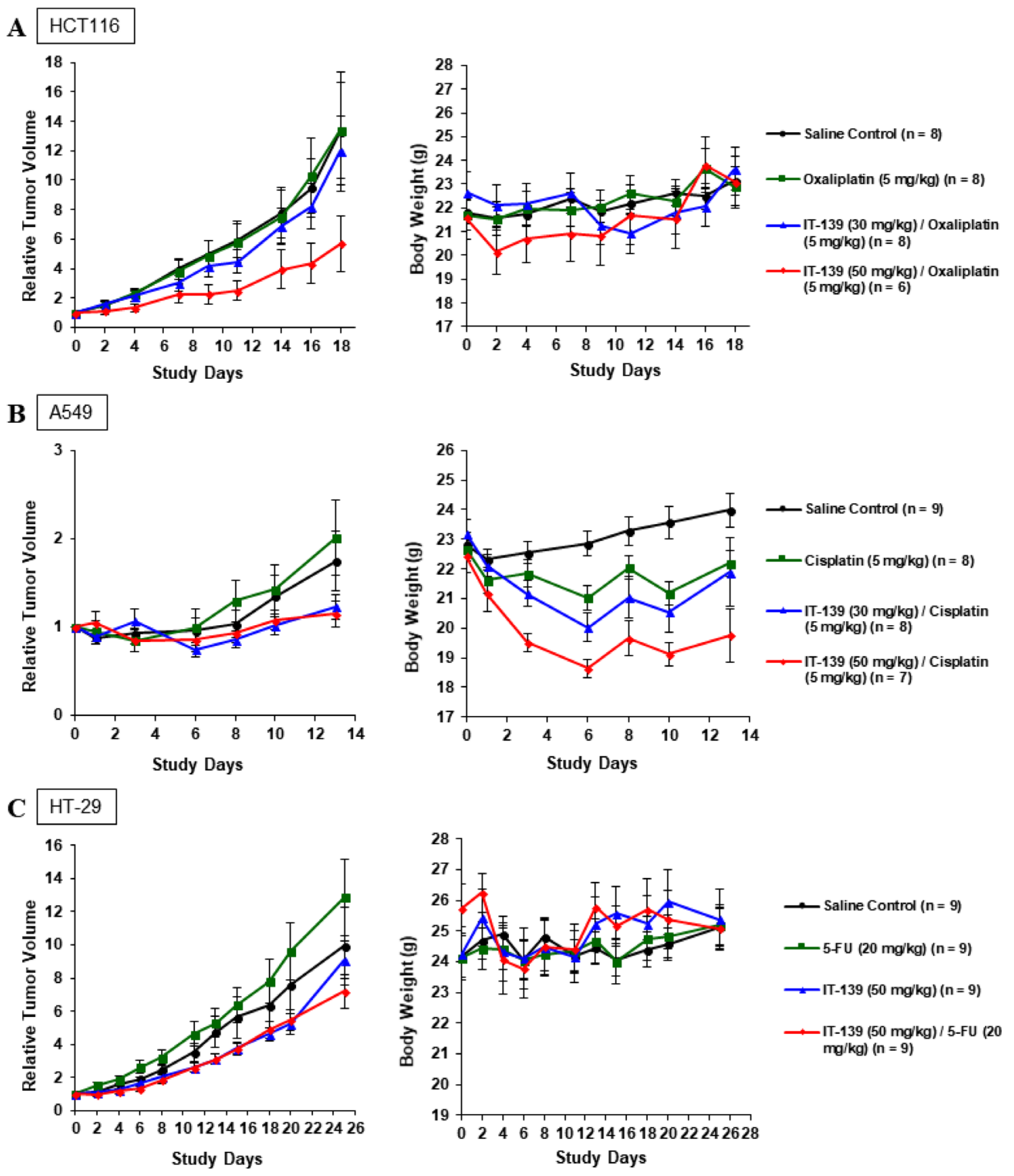

Figure 7: IT-139 treatment in vivo. (A) HCT116 xenograft tumors were treated with saline control, oxaliplatin, or IT-139 in combination with oxaliplatin at 2 doses. Oxaliplatin in combination with IT-139 at $50 \mathrm{mg} / \mathrm{kg}$ had significant anti-tumor efficacy, but this group saw the most weight loss. No animal in this group experienced weight loss exceeding $20 \%$ of weight at study start. (B) A549 xenograft tumors were treated with saline control, cisplatin or IT-139 in combination with cisplatin at 2 doses. Both combination groups saw significant efficacy over the cisplatin treated and control treated groups. The most weight loss was seen in the higher dosed combination group. (C) HT-29 xenograft tumor models were treated with saline control, IT-139 alone or in combination with 5-FU at $50 \mathrm{mg} / \mathrm{kg}$. IT-139 was seen to have an effect in both the monotherapy and combination therapy groups. HT-29 cells are 5-FU resistant as observed by the rate of tumor growth in the 5-FU treated group. Although an initial weight loss was seen in the combination group, all treated animals showed normal weight gain in the study. No treated animals in the three xenograft studies experienced weight loss exceeding $20 \%$ of weight at study start. 
$\mathbf{A}$
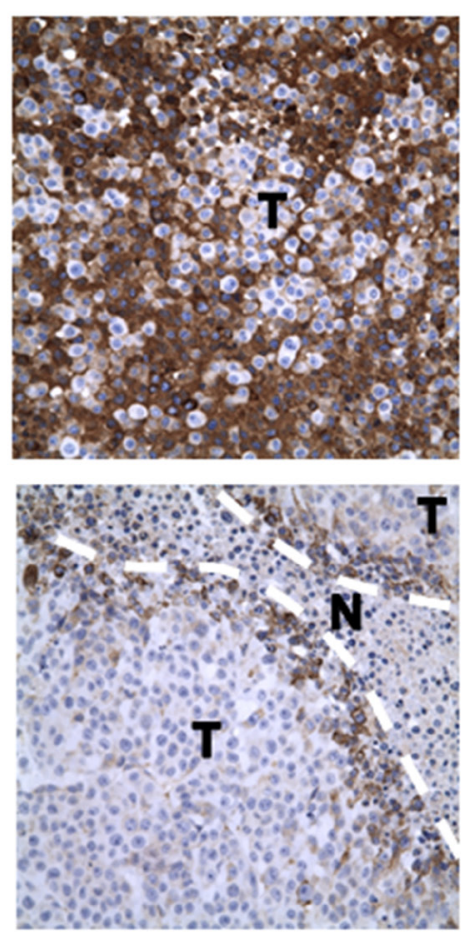

B
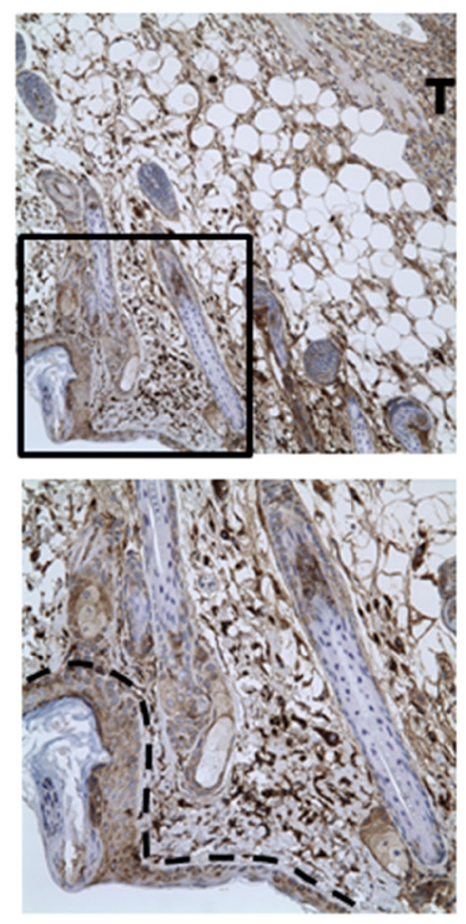

PLX4720
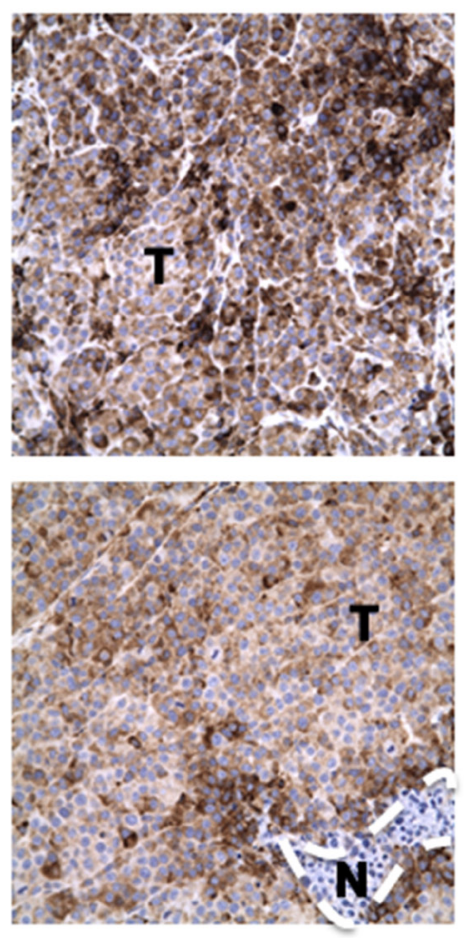

PLX4720+ IT-139
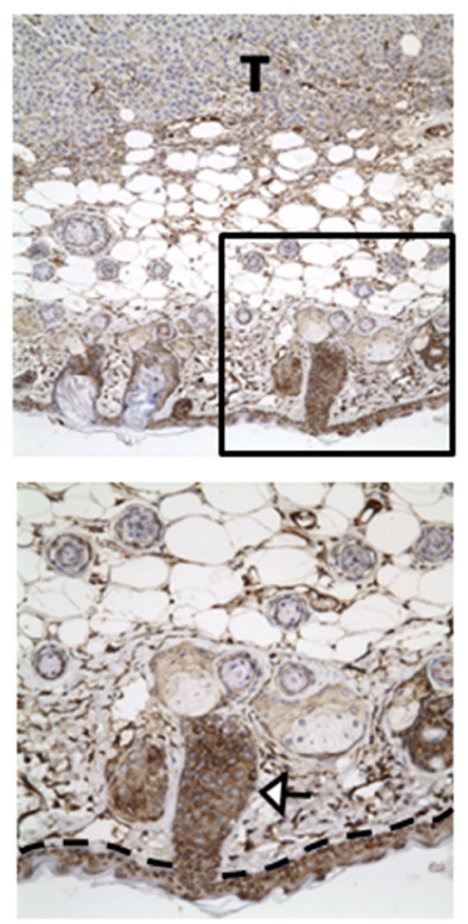

PLX4720+ IT-139
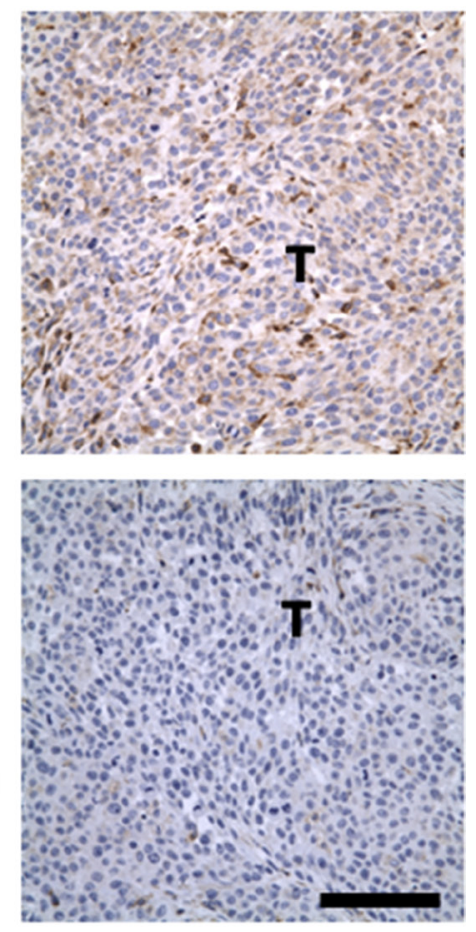

PLX4720 + IT-139
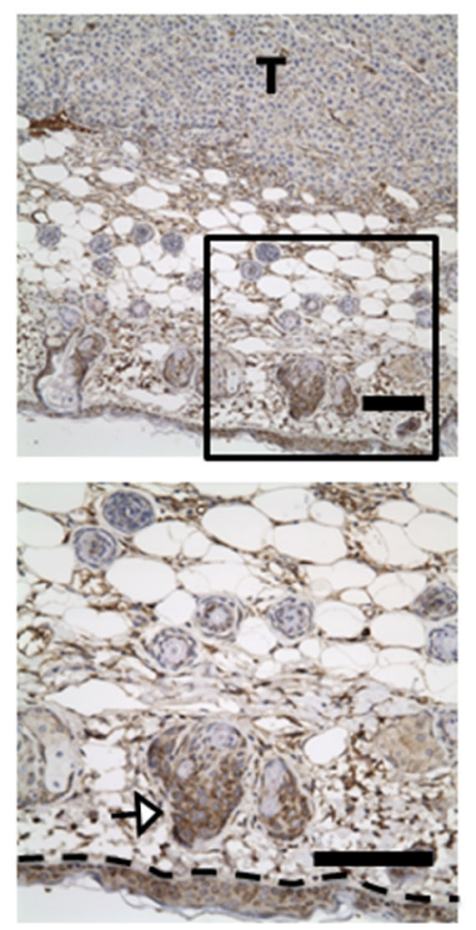

Figure 8: IT-139 preferentially decreases GRP78 expression in tumor cells in vivo. (A) Formalin fixed A375 xenograft tumor sections from mice treated with BRAF inhibitor (PLX4720) alone or in combination with IT-139, or saline as no treatment, were stained for GRP78 expression (brown). T depicts tumor cells and N depicts the necrotic regions. (B) A375 tumors treated with either PLX4720 alone or in combination with IT-139 showed GRP78 expression was unaffected by IT-139 in adjacent non-tumor cells as seen in skin (epidermal layer outlined by black dashed line) and hair follicles as signaled by white arrows. Bottom images are a magnification of the boxed area of the image shown on top. Scale bar, $100 \mu \mathrm{m}$. 
described above. The suppression of GRP78 expression by IT-139 in cancer cell lines involves both transcriptional and post-transcriptional mechanisms and appears to be contextdependent. For example, in HCT116 colon cancer cells, IT139 is able to suppress GRP78 mRNA in both stressed and non-stressed cells, however, the GRP78 protein level was majorly suppressed only in the stressed cells. One reason IT-139's IC50 is in the micromolar range in vitro could be due to GRP78 level not being decreased sufficiently prior to 72 hours to trigger apoptotic pathways. The high micromolar IC50 level is not necessarily a concern for continued clinical development as the MTD determined in the Phase I Clinical Trial was $625 \mathrm{mg} / \mathrm{m}^{2}$ and the pharmacokinetic data values are linear [35].

In non-stressed cells, since there is only low basal synthesis of GRP78, the decrease in GRP78 mRNA level may not affect the overall GRP78 level within a short time period, depending on the stability of GRP78 in the particular cell line. In the case of HCT116 cells, the GRP78 protein has a half-life of over 40 hours (data not shown), hence the IT-139 suppressive effect was detected at the GRP78 mRNA level but not at the protein level after $16 \mathrm{hr}$ of IT-139 treatment. In contrast, in stressed cells, GRP78 is actively being transcribed and translated. Thus, a block in GRP78 transcription by IT-139, as revealed by $G R P 78$ promoter-driven luciferase assay, would inhibit stressinduced upregulation of GRP78 protein. Similarly, IT-139 suppresses stress induction of GRP78 at the transcriptional level in LNCAP, C4-2B, HepG2 and SK-MEL-28 cells. However, in A549 lung cancer cells, IT-139 has no effect on GRP78 mRNA, but moderately elevates its protein level in non-stressed cells and stress induction of GRP78 mRNA was not affected, but GRP78 protein level was suppressed, implying that IT-139 suppresses GRP78 stress-induced expression at the post-transcriptional level in these cells. Interestingly, the expression of HSP70 protein, which shares $50 \%$ amino acid homology with GRP78, is either not affected nor upregulated by IT-139 treatment. This suggests IT-139 is not a general inhibitor of gene transcription, translation or protein stability. While there could be multiple mechanisms mediating the anticancer effect of IT-139, we observed that IT-139 could cause changes in cell morphology and vacuolization likely resulting from ER expansion (data not shown). Such changes in ER structure will activate ER stress, and without the benefit of GRP78 induction to buffer the damage, cell viability could be compromised.

Evidence is emerging that small molecules such as OSU-03012 and HA15 that are capable of suppressing GRP78 translation or its ATPase activity could alleviate drug resistance and radioresistance $[1,45,46]$. Recently Gifford et al., showed that GRP78 is significantly higher in gemcitabine-resistant PDAC and that IT-139 treatment in vivo increased overall survival with gemcitabine over GEM as monotherapy, and in vitro restored sensitivity to cytotoxic drug resistance [47]. The HT-29 cell line is resistant to the chemotherapeutic 5-FU, but we see a response in anti-tumor growth with IT-139 that is increased at the $50 \mathrm{mg} / \mathrm{kg}$ dose. In this model, we staggered the dosing by 24 hours, and the gross toxicity and weight loss was not observed as when we dose at the same time, usually in the same bolus. Our hypothesis is that the reported rate of $1.2-1.5 \mathrm{Ru}$ binding to albumin peaks at 1 hour and drops to $1 \mathrm{Ru}$ per albumin at 24 hours $[48,49]$. The half-life of circulating 5-FU is short [50], so staggering dosing by 24 hours allows 5-FU to be cleared from albumin before IT-139 binds. Also, the rate of albumin uptake could account for the difference in the effect of IT-139 on GRP78 in highly metabolic cancer cells (including HUVECS) compared to normal cells. Also of note, dosing of IT-139 in rodents is not as high as levels dosed in patients. The maximum tolerated dose in mice is $50 \mathrm{mg} / \mathrm{kg}$ that converts to approximately $155 \mathrm{mg} / \mathrm{m}^{2}$ in the clinic. This could potentially be due to the reduced molar concentration of albumin in the mice and account for the data reported in the xenograft models. These results require further investigation to determine optimal dosing strategy for future clinical development.

IT-139 shows striking activity in suppressing GRP78 expression in the treated tumors, alone or in combination with standard therapy. To our knowledge, this is the first demonstration that a small molecule is able to suppress GRP78 expression in vivo. Importantly, GRP78 levels in the normal skin cells adjacent to the tumor was not affected by the IT-139 treatment, in agreement with minimal effect of IT-139 on GRP78 stress induction in non-cancer cells being tested in vitro. The mechanism for this specificity warrants further investigation. In the Phase I dose-escalation open-label study in patients with advanced solid tumors, IT-139 was well tolerated with a manageable toxicity profile. No dose limiting hematologic toxicity was observed and there were no treatment-related deaths in patients treated up to two years with IT-139. Pharmacokinetic (PK) parameters of ruthenium increased proportionally with dose and although there was no evidence of cumulative toxicity, less frequent dosing will be considered for the schedule in future clinical studies. If the stress induction of GRP78 in the tumor is the primary target, then potentially normal cells will be spared and severe adverse events will be reduced. This is especially attractive for combination therapy as increase in toxicity is the rate-limiting step for many current combination dosing regimens.

\section{MATERIALS AND METHODS}

\section{Cells}

HCT116 and HT-29 were cultured in McCoy's 5a Modified Medium; HUVECs, A549 were cultured in F-12K Medium; Capan-1, A375, HepG2 and 293T stable cell line harboring the -169 luciferase construct 
(firefly) [40] were cultured in Dulbecco's Modified Eagle Medium; C4-2B, LNCaP and SK-MEL-28 were cultured in RPMI 1640 Medium. Cell lines for the EC50 and combination assay were obtained from ATCC or the UNC Lineberger Comprehensive Cancer Center and established using standard in vitro culture methods and supplier-recommended media and supplements. All media for the above cells were supplemented with $10 \%$ (v/v) fetal bovine serum, 1\% (v/v) 2 mmol/L L-glutamine and $1 \%$ pen strep. Primary astrocytes (HA) were from ScienCell Research Laboratories and cultured in Astrocyte medium (AM, Cat. \#1801). All cell lines were cultured in a humidified incubator with $5 \% \mathrm{CO}_{2}$ and $95 \%$ air.

\section{Protein extraction and immunoblot analysis}

Cells were treated with IT-139 alone or in combination with tunicamycin or thapsigargin for 16 hours. Cell lysates were prepared and subjected to $10 \%$ or $12 \%$ SDS-PAGE and Western blot analysis. The following primary antibodies were used: GRP78 (1:1000, BD Biosciences \#610978); $\beta$-actin (1:5000, SigmaAldrich, \#A5316); eIF2 $\alpha$ (1:1000, Cell Signaling \#2103); phospho- eIF2 $\alpha$ (1:1000, Cell Signaling \#9721). The secondary antibodies used were as follows: horseradish peroxidase conjugate goat anti-mouse (1:1000, Santa Cruz Biotechnology \#sc-2005) and anti-rabbit (1:1000, Santa Cruz Biotechnology \#sc-2004).

\section{Transfection conditions}

HCT116 cells were transfected with empty pcDNA3 vector or vector expressing FLAG-GRP78 [21] using BioT reagent (Bioland Scientific) according to manufacturer recommendation. The cells were drug-treated for $24 \mathrm{hr}$ and whole cell lysates were harvested and analyzed by Western blots. For detection of apoptotic markers, rabbit anti-Cleaved PARP (5625, Cell Signaling), 1:1000; rabbit anti-Cleaved Caspase-3 (9661, Cell Signaling) 1:1000 were used.

\section{mRNA extraction and analysis}

Total RNA was extracted using TRIzol (Fisher Scientific). Superscript III and oligo(dT) (Fisher Scientific) was used to perform reverse transcription and cDNA was amplified using DNA Taq (NEB). RT-PCR was performed using the following primers: GRP78: Forward: 5'-CAGCACAGACAGATTGACCTAT-3' and Reverse: p3: 5'-GACATCAGCACCGCACTTCTCA-3'; $\beta$-actin: Forward: 5'-TCGTGCGTGACATTAAGGAG-3' and Reverse: 5'-AGCACTGTGTTGGCGTACAG-3'. Xbp 1: Forward: 5'-CTGGAACAGCAAGTGGTAGA-3' and Reverse: 5'-CTGGGTCCTTCTGGGTAGAC-3'. PCR products were resolved on a $2 \%$ agarose gel.

\section{Luciferase assay}

The Luciferase Reporter Assay System (Promega) was used to perform the luciferase assay. For luciferase assay performed on HCT116, the cells were co-transfected with -169 luciferase (firefly) and Renilla luciferase expressing plasmids (Promega) for 4 hours and a dual luciferase assay was performed. Cells were then treated with either tunicamycin or thapsigargin alone or in combination with IT-139 for 6 hours before luciferase expression was tested following manufacturer guidelines. Firefly luciferase enzyme activity was normalized to the Renilla luciferase enzyme activity using the Dual Luciferase Reporter Assay System (Promega).

\section{Immunohistochemistry}

Immunostaining of the paraffin-embedded tissue sections were performed using the antibody for GRP78 (1:400, Abcam \#ab108613). Images were analyzed with ZEN lite imaging software (ZEISS).

\section{Cell viability assays}

All viability assays were run in 96-wellpates at 72 hours. IC50 viability assays were determined by CellTiter Blue (Promega catalog \# G8080) and Cell Titer-Glo Luminescent (Promega catalog \# G7570). EC50 viability assay was evaluated using the MTT Cell Proliferation Assay Kit (ATCC catalog \# 30-1010K).

\section{Animals}

All experiments were carried out in 6-8 week old female nu/nu athymic mice (Charles River labs). The health of all animals was monitored daily by gross observation and analysis of blood samples of sentinel animals. All animals were allowed to acclimatize and recover from any shipping-related stress for a minimum of $72 \mathrm{~h}$ before experimental use. Autoclaved water and irradiated food were provided ad libitum, and the animals were maintained on a 12-h light and dark cycle. Cages, bedding and water bottles were autoclaved before use and were changed weekly. Prior to studies animals were inserted by subcutaneous injection of a radiofrequency identification transponder (RFIDs). Animals were weighed at study start and following treatment, three times a week. All animal experiments were done in accordance with protocols approved by the Institutional Animal Care and Use Committee. All animal treatments were administered intravenously via the lateral tail-vein, except for 5-FU administered intraperitoneal.

\section{Reagents}

Oxaliplatin was purchased from Toronto Research Chemical lot\#8-YM-26-1, 98\% purity. Dissolution of 
oxaliplatin was in $150 \mathrm{mM}$ saline at a concentration of $2 \mathrm{mg} / \mathrm{mL}$. Cisplatin was purchased from TRC lot\#12ABY-28-1, 98\% purity. Dissolution of cisplatin was in $150 \mathrm{mM}$ saline at a concentration of $2 \mathrm{mg} / \mathrm{mL}$. 5-Fluorouracil was obtained from American Pharmaceutical Partners, Inc. Dissolution was in $150 \mathrm{mM}$ saline at a concentration of $10 \mathrm{mg} / \mathrm{mL}$. IT-139 is lot TV-2-149, with a purity of $98 \%$ by HPLC. Dissolution of IT-139 was in 150 $\mathrm{mM}$ saline at a concentration of $10 \mathrm{mg} / \mathrm{mL}$.

\section{Statistical analysis}

Statistical analyses were performed using GraphPad Prism (GraphPad Software, Inc., La Jolla, CA USA). Plotted values for in vivo studies represent means \pm SEM. A student's $t$ test was performed to assess statistical significance. $P$ values of $\leq 0.05$ designated ${ }^{*} P$ values of $\leq$ 0.01 designated as ${ }^{* *}$ and $P$ values of $\leq 0.001$ designated as

${ }^{* * *}$ were considered statistically significant.

\section{ACKNOWLEDGMENTS}

We acknowledge Matt Davis and Sarah Olivo for formatting and figures creation. We thank Lillian Young of the USC Pathology Core facility for assistance in immunohistochemistry. We thank the USC Research Center for Liver Diseases Cell and Tissue Imaging Core for use of the microscope.

\section{CONFLICTS OF INTEREST}

None.

\section{FUNDING}

This research is supported in part by a grant from Intezyne Technologies, Inc. and the National Institutes of Health R01CA027607. A.S.L. is supported by the Freeman Chair and D.F.R by the Diversity Supplement to R01CA027607.

\section{REFERENCES}

1. Lee AS. Glucose-regulated proteins in cancer: molecular mechanisms and therapeutic potential. Nat Rev Cancer. 2014; 14:263-76. https://doi.org/10.1038/nrc3701.

2. Ni M, Lee AS. ER chaperones in mammalian development and human diseases. FEBS Lett. 2007; 581:3641-51. https://doi.org/10.1016/j.febslet.2007.04.045.

3. Luo B, Lee AS. The critical roles of endoplasmic reticulum chaperones and unfolded protein response in tumorigenesis and anticancer therapies. Oncogene. 2013; 32:805-18. https://doi.org/10.1038/onc.2012.130.
4. Wu J, Kaufman RJ. From acute ER stress to physiological roles of the unfolded protein response. Cell Death Differ. 2006; $13: 374$.

5. Hetz C. The unfolded protein response: controlling cell fate decisions under ER stress and beyond. Nat Rev Mol Cell Biol. 2012; 13:89.

6. Luo S, Mao C, Lee B, Lee AS. GRP78/BiP is required for cell proliferation and protecting the inner cell mass from apoptosis during early mouse embryonic development. Mol Cell Biol. 2006; 26:5688-97. https://doi.org/10.1128/ mcb.00779-06.

7. Dong D, Ni M, Li J, Xiong S, Ye W, Virrey JJ, Mao C, Ye R, Wang M, Pen L, Dubeau L, Groshen S, Hofman FM, et al. Critical role of the stress chaperone GRP78/BiP in tumor proliferation, survival, and tumor angiogenesis in transgene-induced mammary tumor development. Cancer Res. 2008; 68:498-505. https://doi.org/10.1158/0008-5472. CAN-07-2950.

8. Lee AS, Brandhorst S, Rangel DF, Navarrete G, Cohen P, Longo VD, Chen J, Groshen S, Morgan TE, Dubeau L. Effects of Prolonged GRP78 Haploinsufficiency on Organ Homeostasis, Behavior, Cancer and Chemotoxic Resistance in Aged Mice. Sci Rep. 2017; 7:40919. https:// doi.org/10.1038/srep40919.

9. Wey S, Luo B, Tseng CC, Ni M, Zhou H, Fu Y, Bhojwani D, Carroll WL, Lee AS. Inducible knockout of GRP78/BiP in the hematopoietic system suppresses Pten-null leukemogenesis and AKT oncogenic signaling. Blood. 2012; 119: 817-25. https://doi.org/10.1182/blood-2011-06-357384.

10. Shen J, Ha DP, Zhu G, Rangel DF, Kobielak A, Gill PS, Groshen S, Dubeau L, Lee AS. GRP78 haploinsufficiency suppresses acinar-to-ductal metaplasia, signaling, and mutant Kras-driven pancreatic tumorigenesis in mice. Proc Natl Acad Sci U S A. 2017; 114:E4020-9. https://doi.org/10.1073/pnas.1616060114.

11. Fu Y, Wey S, Wang M, Ye R, Liao CP, Roy-Burman P, Lee AS. Pten null prostate tumorigenesis and AKT activation are blocked by targeted knockout of ER chaperone GRP78/ BiP in prostate epithelium. Proc Natl Acad Sci U S A. 2008; 105:19444-9.

12. Virrey JJ, Dong D, Stiles C, Patterson JB, Pen L, Ni M, Schonthal AH, Chen TC, Hofman FM, Lee AS. Stress chaperone GRP78/BiP confers chemoresistance to tumorassociated endothelial cells. Mol Cancer Res. 2008; 6:126875. https://doi.org/10.1158/1541-7786.MCR-08-0060.

13. Dong D, Stapleton C, Luo B, Xiong S, Ye W, Zhang Y, Jhaveri N, Zhu G, Ye R, Liu Z, Bruhn KW, Craft N, Groshen S, et al. A critical role for GRP78/BiP in the tumor microenvironment for neovascularization during tumor growth and metastasis. Cancer Res. 2011; 71:2848-57. https://doi.org/10.1158/0008-5472.CAN-10-3151.

14. Li J, Lee AS. Stress induction of GRP78/BiP and its role in cancer. Curr Mol Med. 2006; 6:45-54. 
15. Cook KL, Clarke PA, Clarke R. Targeting GRP78 and antiestrogen resistance in breast cancer. Future Med Chem. 2013; 5:1047-57. https://doi.org/10.4155/fmc.13.77.

16. Li B, Cheng XL, Yang YP, Li ZQ. GRP78 mediates radiation resistance of a stem cell-like subpopulation within the MCF-7 breast cancer cell line. Oncol Rep. 2013; 30:2119-26.

17. Roller C, Maddalo D. The Molecular Chaperone GRP78/ $\mathrm{BiP}$ in the Development of Chemoresistance: Mechanism and Possible Treatment. Front Pharmacol. 2013; 4:10. https://doi.org/10.3389/fphar.2013.00010.

18. Ni M, Zhang Y, Lee A. Beyond the endoplasmic reticulum: atypical GRP78 in cell viability, signalling and therapeutic targeting. Biochem J. 2011; 434:181-8.

19. Ni M, Zhou H, Wey S, Baumeister P, Lee AS. Regulation of PERK signaling and leukemic cell survival by a novel cytosolic isoform of the UPR regulator GRP78/BiP. PLoS One. 2009; 4:e6868. https://doi.org/10.1371/journal.pone.0006868.

20. Ouyang YB, Xu LJ, Emery JF, Lee AS, Giffard RG. Overexpressing GRP78 influences $\mathrm{Ca} 2+$ handling and function of mitochondria in astrocytes after ischemialike stress. Mitochondrion. 2011; 11:279-86. https://doi. org/10.1016/j.mito.2010.10.007.

21. Zhang Y, Liu R, Ni M, Gill P, Lee AS. Cell surface relocalization of the endoplasmic reticulum chaperone and unfolded protein response regulator GRP78/BiP. J Biol Chem. 2010; 285:15065-75. https://doi.org/10.1074/jbc. M109.087445.

22. Zhang Y, Tseng CC, Tsai YL, Fu X, Schiff R, Lee AS. Cancer cells resistant to therapy promote cell surface relocalization of GRP78 which complexes with PI3K and enhances PI(3,4,5)P3 production. PLoS One. 2013; 8:e80071. https://doi.org/10.1371/journal.pone.0080071.

23. Tsai YL, Zhang Y, Tseng CC, Stanciauskas R, Pinaud F, Lee AS. Characterization and Mechanism of Stress-induced Translocation of 78-kilodalton Glucose Regulated Protein (GRP78) to the Cell Surface. J Biol Chem. 2015; 290:804964. https://doi.org/10.1074/jbc.M114.618736.

24. Gonzalez-Gronow M, Selim MA, Papalas J, Pizzo SV. GRP78: a multifunctional receptor on the cell surface. Antioxid Redox Signal. 2009; 11:2299-306. https://doi. org/10.1089/ars.2009.2568.

25. Sato M, Yao VJ, Arap W, Pasqualini R. GRP78 signaling hub a receptor for targeted tumor therapy. Adv Genet. 2010; 69:97-114. https://doi.org/10.1016/s0065-2660(10)69006-2.

26. Gray MJ, Mhawech-Fauceglia P, Yoo E, Yang W, Wu E, Lee AS, Lin YG. AKT inhibition mitigates GRP78 (glucose-regulated protein) expression and contribution to chemoresistance in endometrial cancers. Int J Cancer. 2013; 133:21-30. https://doi.org/10.1002/ijc.27994.

27. Liu R, Li X, Gao W, Zhou Y, Wey S, Mitra SK, Krasnoperov V, Dong D, Liu S, Li D, Zhu G, Louie S, Conti PS, et al. Monoclonal antibody against cell surface GRP78 as a novel agent in suppressing PI3K/AKT signaling, tumor growth, and metastasis. Clin Cancer Res. 2013; 6802:19-11. https:// doi.org/10.1158/1078-0432.ccr-13-1106.

28. Reddy RK, Mao C, Baumeister P, Austin RC, Kaufman RJ, Lee AS. Endoplasmic reticulum chaperone protein GRP78 protects cells from apoptosis induced by topoisomerase inhibitors: role of ATP binding site in suppression of caspase-7 activation. J Biol Chem. 2003; 278:20915-24. https://doi.org/10.1074/jbc.M212328200.

29. Zhou H, Zhang Y, Fu Y, Chan L, Lee AS. Novel mechanism of anti-apoptotic function of $78-\mathrm{kDa}$ glucose-regulated protein (GRP78): endocrine resistance factor in breast cancer, through release of B-cell lymphoma 2 (BCL-2) from BCL-2-interacting killer (BIK). J Biol Chem. 2011; 286:25687-96. https://doi.org/10.1074/jbc.M110.212944.

30. Davidson DJ, Haskell C, Majest S, Kherzai A, Egan DA, Walter KA, Schneider A, Gubbins EF, Solomon L, Chen Z, Lesniewski R, Henkin J. Kringle 5 of human plasminogen induces apoptosis of endothelial and tumor cells through surface-expressed glucose-regulated protein 78. Cancer Res. 2005; 65:4663-72. https://doi.org/10.1158/0008-5472. CAN-04-3426.

31. Wu MJ, Jan CI, Tsay YG, Yu YH, Huang CY, Lin SC, Liu CJ, Chen YS, Lo JF, Yu CC. Elimination of head and neck cancer initiating cells through targeting glucose regulated protein78 signaling. Mol Cancer. 2010; 9:283. https://doi. org/10.1186/1476-4598-9-283.

32. Diaz LA Jr, Williams RT, Wu J, Kinde I, Hecht JR, Berlin J, Allen B, Bozic I, Reiter JG, Nowak MA, Kinzler KW, Oliner KS, Vogelstein B. The molecular evolution of acquired resistance to targeted EGFR blockade in colorectal cancers. Nature. 2012; 486:537-40. https://doi.org/10.1038/ nature11219.

33. Matlock K, Berlow N, Keller C, Pal R. Combination therapy design for maximizing sensitivity and minimizing toxicity. BMC Bioinformatics. 2017; 18:116. https://doi. org/10.1186/s12859-017-1523-1.

34. Al-Lazikani B, Banerji U, Workman P. Combinatorial drug therapy for cancer in the post-genomic era. Nat Biotechnol. 2012; 30:679-92. https://doi.org/10.1038/nbt.2284.

35. Burris HA, Bakewell S, Bendell JC, Infante J, Jones SF, Spigel DR, Weiss GJ, Ramanathan RK, Ogden A, Von Hoff D. Safety and activity of IT-139, a ruthenium-based compound, in patients with advanced solid tumours: a firstin-human, open-label, dose-escalation phase I study with expansion cohort. ESMO Open. 2017; 1:e00154.

36. Keppler BK, Henn M, Juhl UM, Berger MR, Niebl R, Wagner FE. New Ruthenium Complexes for the Treatment of Cancer. In: Baulieu E, Forman D, Ingelman-Sundberg M, Jaenicke L, Kellen J, Nagai Y, Springer G, Träger L, Will-Shahab L, Wittliff J, editors. Ruthenium and Other Non-Platinum Metal Complexes in Cancer Chemotherapy. Springer Berlin Heidelberg; 1989. p. 41-69. https://doi. org/10.1007/978-3-642-74760-1_3.

37. Pizarro AM, Habtemariam A, Sadler PJ. Activation Mechanisms for Organometallic Anticancer Complexes. 
Medicinal Organometallic Chemistry. 2010; 32:21-56. https://doi.org/10.1007/978-3-642-13185-1_2.

38. Messori L, Orioli P, Vullo D, Alessio E, Iengo E. A spectroscopic study of the reaction of NAMI, a novel ruthenium(III) anti-neoplastic complex, with bovine serum albumin. Eur J Biochem. 2000; 267:1206-13.

39. Charuk JH, Pirraglia CA, Reithmeier RA. Interaction of ruthenium red with $\mathrm{Ca} 2(+)$-binding proteins. Anal Biochem. 1990; 188:123-31.

40. Baumeister P, Luo S, Skarnes WC, Sui G, Seto E, Shi Y, Lee AS. Endoplasmic reticulum stress induction of the Grp78/BiP promoter: activating mechanisms mediated by YY1 and its interactive chromatin modifiers. Mol Cell Biol. 2005; 25:4529-40. https://doi.org/10.1128/ MCB.25.11.4529-4540.2005.

41. Chou TC. Theoretical basis, experimental design, and computerized simulation of synergism and antagonism in drug combination studies. Pharmacol Rev. 2006; 58:62181. https://doi.org/10.1124/pr.58.3.10.

42. Thomas S, Sharma N, Gonzalez R, Pao PW, Hofman FM, Chen TC, Louie SG, Pirrung MC, Schonthal AH. Repositioning of Verrucosidin, a purported inhibitor of chaperone protein GRP78, as an inhibitor of mitochondrial electron transport chain complex I. PLoS One. 2013; 8:e65695. https://doi.org/10.1371/journal.pone.0065695.

43. Kim JY, Hwang JH, Cha MR, Yoon MY, Son ES, Tomida A, Ko B, Song SW, Shin-ya K, Hwang YI, Park HR. Arctigenin blocks the unfolded protein response and shows therapeutic antitumor activity. J Cell Physiol. 2010; 224:33-40. https:// doi.org/10.1002/jcp.22085.

44. Shin-ya K, Park HR, Chan SL, Yoichi H, Mattson MP. Effect of veripelostatin, an inhibitor of GRP78 expression on neuronal survival under endoplasmic reticulum stress. 2003 Neuroscience Meeting Planner. New Orleans, LA: Society for Neuroscience; 2003.
45. Booth L, Roberts JL, Cash DR, Tavallai S, Jean S, Fidanza A, Cruz-Luna T, Siembiba P, Cycon KA, Cornelissen CN, Dent P. GRP78/BiP/HSPA5/Dna $\mathrm{K}$ is a universal therapeutic target for human disease. J Cell Physiol. 2015; 230:1661-76. https://doi.org/10.1002/jcp.24919.

46. Cerezo M, Lehraiki A, Millet A, Rouaud F, Plaisant M, Jaune E, Botton T, Ronco C, Abbe P, Amdouni H, Passeron T, Hofman V, Mograbi B, et al. Compounds Triggering ER Stress Exert Anti-Melanoma Effects and Overcome BRAF Inhibitor Resistance. Cancer Cell. 2016; 29:805-19. https:// doi.org/10.1016/j.ccell.2016.04.013.

47. Gifford JB, Huang W, Zeleniak AE, Hindoyan A, Wu H, Donahue TR, Hill R. Expression Of GRP78, Master Regulator Of The Unfolded Protein Response, Increases Chemoresistance In Pancreatic Ductal Adenocarcinoma. Mol Cancer Ther. 2016; 15:1043-52. https://doi. org/10.1158/1535-7163.MCT-15-0774.

48. Heffeter P, Bock K, Atil B, Reza Hoda MA, Korner W, Bartel C, Jungwirth U, Keppler BK, Micksche M, Berger W, Koellensperger G. Intracellular protein binding patterns of the anticancer ruthenium drugs KP1019 and KP1339. J Biol Inorg Chem. 2010; 15:737-48. https://doi.org/10.1007/ s00775-010-0642-1.

49. Bytzek AK, Koellensperger G, Keppler BK, G Hartinger C. Biodistribution of the novel anticancer drug sodium trans-[tetrachloridobis(1H-indazole)ruthenate(III)]

KP-1339/IT139 in nude BALB/c mice and implications on its mode of action. J Inorg Biochem. 2016; 160:250-5. https://doi.org/10.1016/j.jinorgbio.2016.02.037.

50. Schilsky RL. Biochemical and clinical pharmacology of 5-fluorouracil. Oncology (Williston Park). 1998; 12:13-8. Available from http://www.ncbi.nlm.nih.gov/ pubmed/9830619. 